\title{
NUEVAS OBSERVACIONES SOBRE LA VEGETACIÓN DEL SUR DEL PERÚ.DEL DESIERTO PACÍFICO AL ALTIPLANO
}

\author{
Antonio GALÁN DE MERA ${ }^{1 *}$, Eliana LINARES PEREA², \\ José CAMPOS DE LA CRUZ ${ }^{3}$ y José A. VICENTE ORELLANA ${ }^{1}$
}

\author{
${ }^{1}$ Laboratorio de Botánica, Universidad San Pablo-CEU, Apartado 67, 28660- Boadilla del Monte, \\ Madrid, España \\ ${ }^{2}$ Estudios Fitogeográficos del Perú, Sánchez Cerro 219, Manuel Prado, Paucarpata, Arequipa, Perú \\ ${ }^{3}$ Museo de Historia Natural, Universidad Nacional Mayor de San Marcos, Apartado 140434, \\ Lima- 14, Perú \\ *Autor para correspondencia: agalmer@ceu.es
}

Recibido el 9 de junio de 2009, aceptado para su publicación el 27 de junio de 2009

Publicado "on line" en septiembre de 2009

\begin{abstract}
RESUMEN. Nuevas observaciones sobre la vegetación del Sur del Perú. Del Desierto Pacifico al Altiplano. En este trabajo, aportamos novedades sobre la vegetación del S del Perú desde el Desierto Pacífico a las cumbres del Altiplano. Como resultado se describen 19 asociaciones distribuidas entre diferentes formaciones vegetales: arbustedas y bosques climácicos de la costa [Echinopsio chalaensis-Randietum armatae (arbustedas espinosas termotropicales semiáridas), Caesalpinio spinosae-Myrcianthetum ferreyrae (bosques termotropicales secos)], vegetación herbácea de las lomas costaneras [Nolano spathulatae-Palauetum dissectae (herbazales de suelos arenosos poco estabilizados), Hoffmannseggio mirandae-Palauetum weberbaueri (herbazales de suelos arenosos estabilizados)], vegetación de los saladares de la costa [Cresso truxillensis-Distichlietum spicatae (comunidad de suelos arenosos y salinos), Cypero laevigati-Distichlietum spicatae (vegetación de suelos húmedos salinos), Lippio nodiflorae-Paspaletum vaginati (pastizales de las costa pacífica inundados por aguas salobres), Schoenoplectetum olneyi-americani (juncales de la costa pacífica), Sporobolo virginiciDistichlietum spicatae (pastizales de la costa)], monte ribereño de la costa [Plucheetum absinthioidis (arbustedas halófilas)], comunidades de freatófitos de las quebradas [Acacio macracanthae-Tecometum guarumis (asociación termo-mesotropical de freatófitos del departamento de Ica), Schino mollis-Tecometum arequipensis (asociación termo-mesotropical de freatófitos del SE del departamento de Arequipa y NO del de Moquegua), Schino mollis-Tecometum tanaeciiflorae (asociación termo-mesotropical de freatófitos de las quebradas del río Colca)], comunidades de cactáceas columnares [Armatocereo riomajensis-Euphorbietum apurimacensis (vegetación de cactus y arbustos de Euphorbia, mesotropical semiárida del cañón del Colca en Arequipa), Weberbauerocereo rahuii-Browningietum candelaris (vegetación de cactus, termotropical árida de los valles del Cotahuasi, Colca y Siguas en Arequipa), Weberbauerocereo rahuii-Corryocactetum brevistyli (vegetación de cactus, mesotropical árida-semiárida de los cañones del Cotahuasi y Colca) y Weberbauerocereo torataensis-Corryocactetum brevistyli (vegetación de cactus, mesotropical árida del valle de Torata en Moquegua)], vegetación rupícola [Polyachyro sphaerocephali-Puyetum densiflorae (comunidades rupícolas supratropicales del cañón del Colca en Arequipa)], y pajonal-tolares y puyales [Baccharido tricuneatae-Puyetum raimondii (comunidades con Puya raimondii orotropicales subhúmedas), Diplostephio
\end{abstract}


tovari-Festucetum orthophyllae (pajonal-tolares orotropicales seco-subhúmedos de valles interandinos)]. Además se describen 4 alianzas y 3 órdenes [Grindelion glutinosae y Citharexylo flexuosi-Crotonetalia alnifolii (arbustedas y bosques de las lomas del S del Perú), Ludwigio octovalvis-Paspalion vaginati y Schoenoplectetalia olneyi-americani (pastizales y juncales del Desierto Pacífico), Plucheion absinthioidis (arbustedas costeras del sector Arequipeño), y Sarcocornio neei-Distichlion spicatae y Sarcocornietalia neei (vegetación de los saladares de la costa pacífica peruana y chilena)], y 1 clase fitosociológica [Carico candicantisCaesalpinietea spinosae (bosques y arbustedas termo-mesotropicales seco-semiáridos andinas occidentales]. También se presenta un esquema sintaxonómico comentado con todas las unidades fitosociológicas reconocidas hasta el momento en el S del Perú.

Palabras clave. Vegetación, sintaxonomía, sur del Perú.

ABSTRACT. New observations about the vegetation of Southern Peru. From the Pacific Desert to the high Andean plateau. In this work, we present new reports about the vegetation of southern Peru, from the Pacific Desert to the highland of the Altiplano: As result, 19 new associations distributed in different plant formations are described: coastal shrublands and climax forests [Echinopsio chalaensis-Randietum armatae (semiarid thermotropical spiny schrubs), Caesalpinio spinosae-Myrcianthetum ferreyrae (dry thermotropical forests)], herb communities of the coastal hills [Nolano spathulatae-Palauetum dissectae (herbs on low stabilized sandy soils), Hoffmannseggio mirandae-Palauetum weberbaueri (herbs on stabilized sandy soils)], coastal vegetation on salt soils [Cresso truxillensis-Distichlietum spicatae (plant community on salt and sandy soils), Cypero laevigati-Distichlietum spicatae (vegetation on humid salt soils), Lippio nodifloraePaspaletum vaginati (grasslands of the Pacific Coast flooded by salt waters), Schoenoplectetum olneyiamericani (Rushes of the Pacific Coast), Sporobolo virginici-Distichlietum spicatae (coastal grasslands)], coastal riverside shrublands [Plucheetum absinthioidis (halophilous shrub communities)], freatic plant communities of the ravines [Acacio macracanthae-Tecometum guarumis (freatic thermo-mesotropical association of Ica department), Schino mollis-Tecometum arequipensis (freatic thermo-mesotropical association of SE Arequipa and NW Moquegua departments), Schino mollis-Tecometum tanaeciiflorae (freatic thermo-mesotropical association of the affluents of the Colca river in Arequipa)], columnar cactus plant communities [Armatocereo riomajensis-Euphorbietum apurimacensis (semiarid mesotropical cactus and Euphorbia-shrubs vegetation of the Colca canyon in Arequipa), Weberbauerocereo rahuii-Browningietum candelaris (arid thermotropical cactus vegetation of the Cotahuasi, Colca and Siguas valleys in Arequipa), Weberbauerocereo rahuii-Corryocactetum brevistyli (arid-semiarid mesotropical cactus vegetation of the Cotahuasi and Colca canyons in Arequipa) and Weberbauerocereo torataensis-Corryocactetum brevistyli (arid mesotropical cactus vegetation of the Torata valley in Moquegua), rock plant vegetation [Polyachyro sphaerocephali-Puyetum densiflorae (supratropical rock plant communities of the Colca canyon in Arequipa)], and grass-shrublands and Puya plant communities [Baccharido tricuneatae-Puyetum raimondii (subhumid orotropical plant communities with Puya raimondii), Diplostephio tovari-Festucetum orthophyllae (drysubhumid orotropical grass-shrublands of the interandean valleys). Moreover, 4 alliances and three orders are described [Grindelion glutinosae and Citharexylo flexuosi-Crotonetalia alnifolii (shrublands and forests of the coastal hills of Southern Perú), Ludwigio octovalvis-Paspalion vaginati and Schoenoplectetalia olneyiamericani (grasslands and rushes of the Pacific Desert), Plucheion absinthioidis (coastal shrublands of the Arequipeño sector), and Sarcocornio neei-Distichlion spicatae and Sarcocornietalia neei (salt vegetation of the Peruvian and Chilean pacific coast)], and 1 phytosociological class [Carico candicantis-Caesalpinietea spinosae (dry-semiarid thermo-mesotropical shrublands and forests of the neotropical Pacific Desert and occidental Andean slops].

Also, a commented syntaxonomical scheme with the phytosociological units for the Southern Peru vegetation is presented.

Key words. Vegetation, syntaxonomy, Southern Peru.

\section{INTRODUCCIÓN Y OBJETIVOS}

La vegetación del Perú ha atraído a numerosos botánicos de todo el mundo desde la publicación de la obra de Weberbauer (1945). Sin embargo, aún hay muchos vacíos sobre la 
flora y la vegetación de regiones que comienzan a estudiarse en la actualidad. En el norte, no solo se están describiendo especies nuevas para la ciencia, sino que cada vez se publican más datos sobre el páramo peruano, los bosques, $\mathrm{y}$ de su relación con los de Ecuador y Colombia (Sánchez Vega et al., 2005; Weigend et al., 2005; Marcelo Peña et al., 2006). Del sur, al que ya nos dedicamos en otros trabajos (Galán de Mera et al., 2003a, 2003b), se han aportado algunas publicaciones desde la de Nicholson (1939), autor poco conocido que intentó asentar en el Perú las ideas de la asociación y sucesión de Huguet del Villar (1929). En el sur, podemos hablar de aportes florísticos y ecológicos locales (Linares Perea \& Benavides, 1995; Puig et al., 2002; Linares Perea, 2005; Kuentz et al., 2007); desde el punto de vista fitosociológico solo podemos destacar el de Gutte \& Müller (1985) y algunas otras pequeñas contribuciones que añadimos a las ya mencionadas (Galán de Mera \& Vicente Orellana, 1996; Galán de Mera \& Gómez Carrión, 2001; Galán de Mera et al., 2002a).

En este trabajo tratamos de completar aquel sobre la vegetación de la alta montaña andina (Galán de Mera et al., 2003a) con la del desierto costero y los valles interandinos del departamento de Arequipa, así como con la publicación de algunos inventarios de los departamentos de Ica, Moquegua y Tacna. Con los nuevos sintáxones que aportamos nos disponemos a hacer un importante avance sobre la diversidad de comunidades vegetales del sur del Perú.

\section{MATERIAL Y MÉTODOS}

El levantamiento de inventarios fitosociológicos para comparar la vegetación de distintos territorios se va haciendo cada vez más frecuente en América Central, El Caribe y América del Sur (Huber \& Riina, 1997; Galán de Mera \& Vicente Orellana, 2006), a los que podemos incorporar otras metodologías muy afines (Phillips \& Miller, 2002) basadas en la combinación florística de las comunidades vegetales, y que van orientadas a conocer la biodiversidad de regiones. La síntesis de caracteres ecológicos y la flora de los territorios nos viene dada al usar el método fitosociológico de Braun-Blanquet (1932), plasmado en tablas fitosociológicas que resultan de la comparación de inventarios publicados procedentes de otras zonas (Borhidi, 1991, 1996; Borhidi et al., 1979, 1983; Rivas-Martínez \& Tovar, 1982; Gutte, 1985, 1986; Müller, 1985a; Müller \& Gutte, 1983, 1985; Seibert \& Menhofer, 1991, 1992; Navarro, 1993; Luebert \& Gajardo, 2000, 2005; Navarro \& Maldonado, 2005).

\section{Nomenclatura y colecciones}

La nomenclatura y autorías de los táxones tratados están de acuerdo con Linares Perea (1991) y Brako \& Zarucchi (1993), actualizados en Solomon (2009). Los sintáxones atienden al Código Internacional de Nomenclatura Fitosociológica (Izco \& Del Arco, 2003). Los nombres vernáculos empleados para designar territorios, plantas y comunidades vegetales proceden de Soukup (1987), Pulgar Vidal (1996) y Brack Egg (1999).

Para la determinación de las plantas se han consultado los herbarios AQP, F, HUSA, MO, NY, US, USM y USP; los especímenes recolectados se conservan en los herbarios AQP y USP.

\section{El territorio estudiado}

La zona de estudio (fig. 1) comprende sobre todo el departamento de Arequipa, aunque para comparar y completar ciertos aspectos de la vegetación, incluimos datos de los departamentos de Ica, Moquegua y Tacna.

El departamento de Arequipa se encuentra situado entre los $14^{\circ} 60^{\prime}$ y $17^{\circ} 30^{\prime} \mathrm{S}$, y $\operatorname{los} 71^{\circ}$ y $75^{\circ} \mathrm{O}$. Entre sus accidentes geográficos destacan numerosos volcanes (vulcanismo terciario y cuaternario) y casquetes glaciares 


\begin{tabular}{lcccccc}
\hline Estación meteorológica & T & M & m & P & It & Descripción bioclimática \\
\hline $\begin{array}{l}\text { Mollendo, 30 m } \\
\left(17^{\circ} 02^{\prime} \mathrm{S}, 72^{\circ} 01^{\prime} \mathrm{O}\right)\end{array}$ & 18,7 & 17,7 & 13,8 & 17 & 502 & Termotropical hiperárido \\
$\begin{array}{l}\text { Camaná, } 40 \mathrm{~m} \\
\left(16^{\circ} 37^{\circ} \mathrm{S}, 72^{\circ} 42^{\prime} \mathrm{O}\right)\end{array}$ & 19,3 & 19,7 & 12,8 & 15 & 513 & Termotropical hiperárido \\
$\begin{array}{l}\text { La Pampilla, } 2350 \mathrm{~m} \\
\left(16^{\circ} 25^{\prime} \mathrm{S}, 71^{\circ} 31^{\prime} \mathrm{O}\right)\end{array}$ & 14,9 & 22,3 & 2,5 & 68 & 397 & Mesotropical árido \\
$\begin{array}{l}\text { Cotahuasi, } 2683 \mathrm{~m} \\
\left(15^{\circ} 12^{\prime} \mathrm{S}, 72^{\circ} 54^{\prime} \mathrm{O}\right)\end{array}$ & 15,2 & 22,0 & 6,9 & 441 & 247 & Mesotropical semiárido \\
$\begin{array}{l}\text { Pampacolca, 3000 } \mathrm{m} \\
\left(15^{\circ} 42^{\prime} \mathrm{S}, 72^{\circ} 34^{\prime} \mathrm{O}\right)\end{array}$ & 12,8 & 19,5 & 5,6 & 227 & 379 & Mesotropical semiárido \\
$\begin{array}{l}\text { Sibayo, 3810 m } \\
\left(15^{\circ} 28^{\prime} \mathrm{S}, 71^{\circ} 27^{\prime} \mathrm{O}\right)\end{array}$ & 8,3 & 16,6 & $-8,1$ & 562 & 78 & Orotropical subhúmedo \\
$\begin{array}{l}\text { Angostura, } 4155 \mathrm{~m} \\
\left(15^{\circ} 11^{\prime} \mathrm{S}, 71^{\circ} 39^{\prime} \mathrm{O}\right)\end{array}$ & 5,6 & 13,3 & $-11,1$ & 659 & 78 & Orotropical subhúmedo \\
$\begin{array}{l}\text { Caylloma, } 4320 \mathrm{~m} \\
\left(15^{\circ} 11^{\prime} \mathrm{S}, 71^{\circ} 46^{\prime} \mathrm{O}\right)\end{array}$ & 4,8 & 12,2 & $-8,7$ & 639 & 83 & Orotropical subhúmedo \\
$\begin{array}{l}\text { Imata, } 4436 \mathrm{~m} \\
\left(15^{\circ} 50^{\prime} \mathrm{S}, 71^{\circ} 05^{\prime} \mathrm{O}\right)\end{array}$ & 3,2 & 11,5 & $-12,5$ & 569 & 22 & Criorotropical subhúmedo \\
\hline
\end{tabular}

Tabla 1. Variables climáticas, índices bioclimáticos y descripción bioclimática de estaciones meteorológicas del territorio estudiado, de acuerdo con la metodología de Rivas-Martínez (1999)[T: temperatura media anual $\left({ }^{\circ} \mathrm{C}\right), \mathrm{M}$ : temperatura media de las máximas del mes más frío $\left({ }^{\circ} \mathrm{C}\right), \mathrm{m}$ : temperatura media de las mínimas del mes más frío $\left({ }^{\circ} \mathrm{C}\right)$, P: precipitación media anual $(\mathrm{mm})$, It: índice de termicidad]. Climatic variables, bioclimatic indexes and bioclimatic description of meteorological stations of the studied territory according to the methodology of Rivas-Martinez (1999) [T: mean annual temperature $\left({ }^{\circ} \mathrm{C}\right)$, M: mean highest temperature of the coldest month $\left({ }^{\circ} \mathrm{C}\right), \mathrm{m}$ : mean lowest temperature of the coldest month $\left({ }^{\circ} \mathrm{C}\right), P:$ mean annual precipitation (mm), It: thermicity index].

(nevados) que forman las mayores altitudes del territorio estudiado: Ampato (6288 m), Chila (5655 m), Colluncuya (5556 m), Coropuna (6305 m), Firula (5498 m), Huachuhunca (5315 $\mathrm{m})$, Huajrahuire (5438 m), Huarancante (5114 $\mathrm{m})$, Misti (5822 m), Pichu-Pichu (5415 m), Sabancaya (5976 m) y Solimana (6093 m).

El relieve volcánico, con cuarcitas sedimentarias, y areniscas y pizarras con un manto superior de areniscas y andesitas (Treacy, 1994), formó los valles más profundos que recorren el territorio de $\mathrm{E}$ a $\mathrm{O}$; el cañón del río Colca y el del río Cotahuasi profundizan $3000 \mathrm{~m}$ originando grandes contrastes entre la vegetación de las laderas volcánicas y el fondo de los valles. Bajo los $2000 \mathrm{~m}$ y hasta los 1000 $\mathrm{m}$, se extiende la barrera interdesértica (Galán de Mera et al., 1997), localmente llamada "tablazo desértico", una gran planicie abiótica, con sedimentación fluvial y eólica cuaternarias. Ésta termina en la cordillera de la costa, complejo metamórfico precámbrico basal de la costa (IGM, 1975), con altitudes entre 1200 m y $1400 \mathrm{~m}$, en cuya vertiente occidental se dejan sentir las nieblas causadas por la corriente marítima fría de Humboldt (Koepcke, 1961; Rauh, 1979).

El endorreismo también está presente en todo el territorio; al S del departamento de Arequipa destacan las lagunas de Salinas (4000 m de altitud) y Aguada Blanca (3000 $\mathrm{m}$ de altitud), y en la gran planicie abiótica desértica son frecuentes las eflorescencias salinas. Son asimismo características las áreas 
de saladares costeros y las playas, con ausencia de vegetación.

\section{Bioclimatología}

Aunque en la mayoría de estudios sobre vegetación del Perú continúa usándose el método de Holdridge (1960) a pesar de sus limitaciones al establecer un paralelismo entre clima y vegetación, nosotros, como en otras ocasiones, preferimos utilizar la metodología universal de Rivas-Martínez et al. (1999), puesto que el índice de termicidad (It) es coincidente con cinturas altitudinales y latitudinales de vegetación:

$$
\mathrm{It}=(\mathrm{T}+\mathrm{M}+\mathrm{m}) 10
$$

[T: temperatura media anual $\left({ }^{\circ} \mathrm{C}\right), \mathrm{M}$ : temperatura media de las máximas del mes más frío $\left({ }^{\circ} \mathrm{C}\right), \mathrm{m}$ : temperatura media de las mínimas del mes más frío $\left.\left({ }^{\circ} \mathrm{C}\right)\right]$

Según la última aproximación que realizamos para el Perú (Kuentz et al., 2007), en el departamento de Arequipa están representados 5 pisos bioclimáticos tropicales que coinciden con intervalos altitudinales aproximados [termotropical $(\mathrm{It}=490-730 ; 0-2100 \mathrm{~m})$, mesotropical (It $=320-490 ; 2100-3100 \mathrm{~m})$, supratropical $(\mathrm{It}=160-320 ; 3100-3800 \mathrm{~m})$, orotropical (It $=50-160 ; 3800-4800 \mathrm{~m}) \mathrm{y}$ criorotropical (It $<50 ;>4800 \mathrm{~m}$ )], matizados por diferentes tipos de intervalos de humedad $(\mathrm{mm})$ [ultrahiperárido $(\mathrm{P}<5)$, hiperárido $(\mathrm{P}$ = 5-30), árido $(\mathrm{P}=30-100)$, semiárido $(\mathrm{P}=$ 100-300), seco ( $\mathrm{P}=300-500)$ y subhúmedo ( $\mathrm{P}$ $=500-900)$ ].

En la tabla 1 se representan las estaciones meteorológicas del departamento de Arequipa (SENAMHI- Servicio Nacional de Meteorología e Hidrología del Perú; Rivas-Martínez, 2009) con su diagnosis bioclimática.

El piso termotropical hiperárido costero presenta un marcado carácter mediterráneo debido al régimen de precipitaciones con máximos entre julio y septiembre, acompañado de un descenso de las medias de las temperaturas causado por la influencia de la corriente marítima de Humboldt (Galán de Mera \& Vicente Orellana, 2007). Aunque las estaciones meteorológicas de la costa del centro y $\mathrm{S}$ del Perú indican un bioclima termotropical hiperárido o ultrahiperárido (Rivas-Martínez et al., 1988), hay lugares de la costa de Arequipa, donde por cripto-precipitación de las nieblas causadas por la corriente de Humboldt, podemos alcanzar un ombroclima árido (Atico, Cachendo) con la presencia de comunidades de cactáceas columnares con Neoraimondia arequipensis Backeb., e incluso seco (Atiquipa), donde podemos observar los bosques de Caesalpinia spinosa (Molina) Kuntze y Myrcianthes ferreyrae (McVaugh) McVaugh.

Reconocemos cada piso de vegetación del departamento de Arequipa por la presencia de determinadas especies bioindicadoras (tab. 2); además éstos son coincidentes en gran parte con

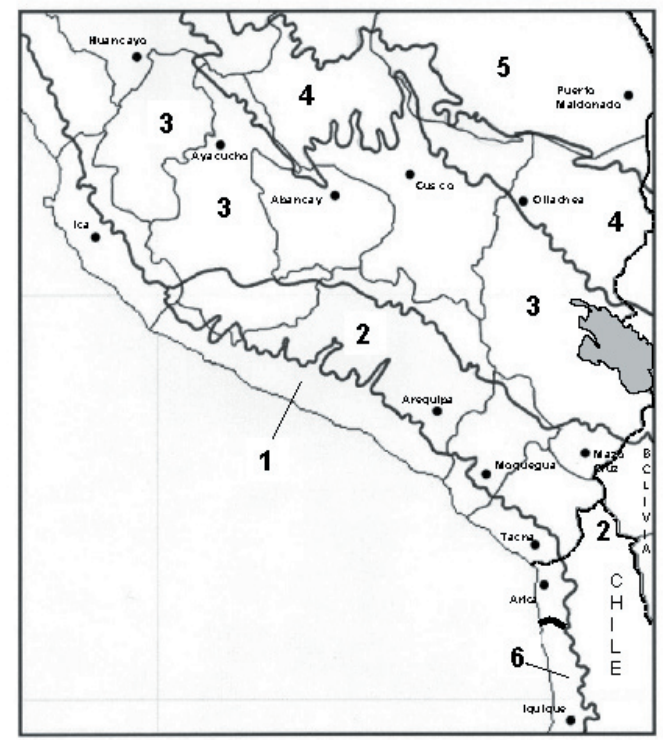

Figura 1. Provincias fitogeográficas del S del Perú. Phytogeographic provinces of Southern Peru. 1- Limeño-Ariqueña, 2- Oruro-Arequipeña, 3Ancashino-Paceña, 4- Urubambense, 5- Madre de Dios, 6- Atacama (Chile). 
la nomenclatura paisajística indígena (lenguas runa shimi y aymara) donde cada piso incluye un uso tradicional (Pulgar Vidal, 1996).

En los pisos termo- y mesotropical encontramos cultivos de regadío con una mezcla de plantas que entraron especialmente en la época colonial y otras procedentes de la agricultura incaica (Popenoe et al., 1989) [Capsicum pubescens Ruiz \& Pav. ("rocoto"), Carica pubescens Lenné \& C. Koch ("papaya arequipeña"), Medicago sativa L. ("alfalfa"), Persea americana Mill. ("palto"), Phaseolus vulgaris L. ("poroto"), Solanum phureja Juz. \& Bukasov ("papa phureja"), etc.], y se cultivan en la costa y en la campiña arequipeña mesotropical, regada por los ríos Chili y Huasamayo. De los pisos supratropical y niveles inferiores del orotropical es característica una amplia diversidad de tubérculos [Oxalis tuberosa Molina ("oca"), Solanum ahanhuiri Juz. \& Bukasov ("papa de chuño"), Tropaeolum tuberosum Ruiz \& Pav. ("mashua"), Ullucus tuberosus Caldas ("ullucu"), etc.] y frutos de Amarantáceas y Quenopodiáceas [Amaranthus caudatus L. ("kiwicha"), Chenopodium pallidicaule Aellen ("kañiwa"), Chenopodium quinoa Willd. ("quinoa”)].

\section{Fitogeografía}

De acuerdo con la sectorización fitogeográfica propuesta recientemente para el centro de América del Sur (Galán de Mera \& Linares Perea, 2008), la del sur del Perú es la siguiente (fig. 1):

Reino Neotropical

Subreino Andino-Patagónico

Región Andina

Subregión del Desierto Pacífico

1. Provincia Limeño-Ariqueña

2. Provincia de Atacama (Chile)

Subregión Paramuno-Puneña

3. Provincia Oruro-Arequipeña

4. Provincia Ancashino-Paceña

Subregión de la Ceja de Montaña
5. Provincia Urubambense

Subreino Caribeo-Amazónico

Región Amazónica

6. Provincia de Madre de Dios

En trabajos anteriores (Galán de Mera et al., 2004) incluíamos en la subregión Paramuno-Puneña a la provincia CoquimboTruxillense basándonos en su gran diversidad de comunidades de cactáceas columnares, y siguiendo las propuestas de otros autores peruanos (Tovar, 2002; Brack Egg \& Mendiola Vargas, 2004); sin embargo, dichas comunidades forman parte de la cliserie altitudinal (RivasMartínez, 2007) de la cordillera, que comienza con una vegetación dispersa de cactáceas con una flora muy diferente entre los departamentos de Ica y Tacna, pertenecientes a la provincia Oruro-Arequipeña, y la de los departamentos de Lima y Ancash, que se incluyen en la provincia Ancashino-Paceña.

En esta ocasión solo nos ocupamos de las provincias Limeño-Ariqueña y OruroArequipeña, a las que pertenece la vegetación estudiada.

Dentro de la provincia Limeño-Ariqueña habíamos distinguido al sector Arequipeño (Galán de Mera et al., 1997), desde el valle de Nazca a la Quebrada de Camarones (Chile), por su riqueza en especies endémicas (Bruns, 1929; Ferreyra, 1953; Müller, 1985b; Dillon et al., 2007): Cistanthe tovari A. Galán, Echinopsis chalaensis (Rauh \& Backeb.) Friedrich \& G.D. Rowley, Myrcianthes ferreyrae, Neoporteria islayensis (Foerster) Donald \& G.D. Rowley, Nolana arequipensis M.O. Dillon \& Quip., N. chancoana M.O. Dillon \& Quip., N. pallidula I.M. Johnst., N. spathulata Ruiz \& Pav., Palaua weberbaueri Ulbr., Senecio mollendoensis Cabrera, Tillandsia werdermannii Harms, Weberbauerella brongniartioides Ulbr., W. raimondiana Ferreyra.

Son endemismos territoriales de la provincia Oruro-Arequipeña: Armatocereus riomajensis Rauh \& Backeb., Carica augusti 


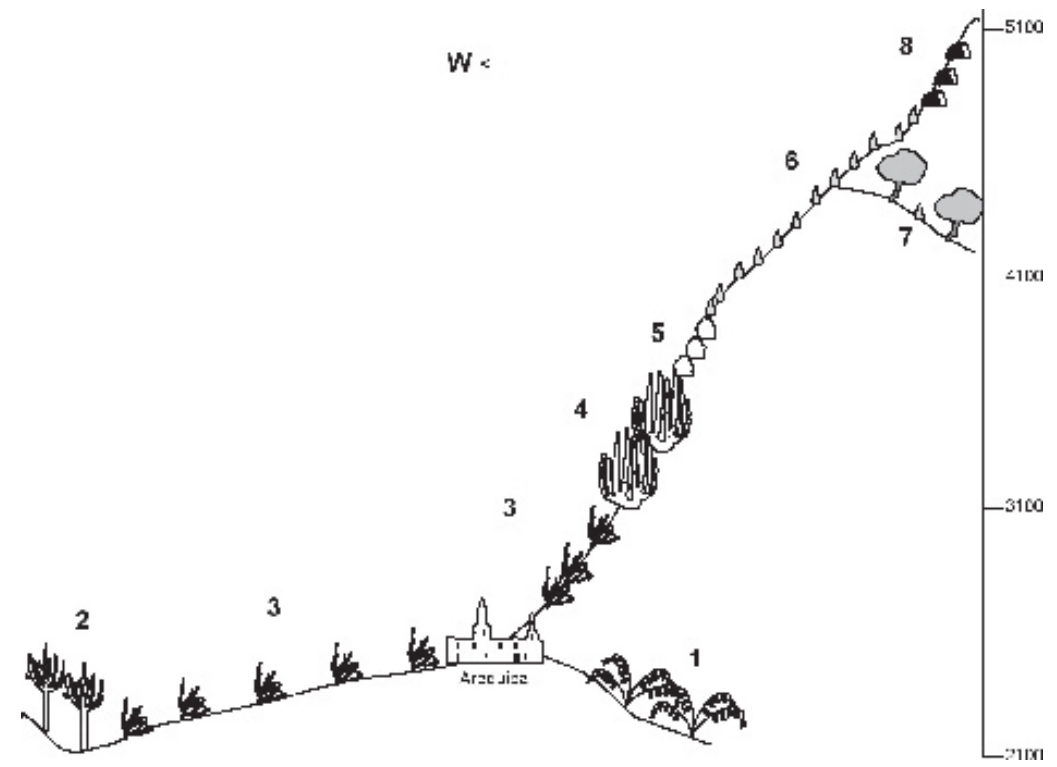

Figura 2. Esquema de la vegetación desde Uchumayo a las cumbres del complejo volcánico del Chachani (departamento de Arequipa). 1- Vegetación freatófila termo-mesotropical con Tecoma arequipensis o "cahuato" (Schino mollis-Tecometum arequipensis), 2- Comunidades termotropicales áridas con Browningia candelaris o cáctus candelabro (Weberbauerocereo weberbaueri-Browningietum candelaris), 3- Comunidades mesotropicales áridas con Corryocactus brevistylus (Weberbauerocereo weberbaueriCorryocactetum brevistyli), 4- Comunidades supratropicales semiáridas con Oreocereus hendriksenianus y Corryocactus brevistylus, 5- Matorrales o "tolares" supratropicales semiárido-secos (Diplostephio tacorensis-Parastrephietum lepidophyllae), 6- Pastizales con matorrales o "pajonal-tolares" orotropicales seco-subhúmedos (Parastrephio lucidae-Festucetum orthophyllae), 7- Bosques orotropicales semiáridosecos o "queñuales" (Chuquirago rotundifoliae-Polylepidetum rugulosae), 8- Complejo de vegetación oro-criorotropical de pedregales [Parastrephio lucidae-Festucetum orthophyllae azorelletosum compactae (pedregales fijos), Nototricho obcuneatae-Xenophylletum poposi (pedregales móviles)]. Vegetation scheme from Uchumayo to the summits of the volcanic complex Chachani (Arequipa department). 1- Thermomesotropical freatofilous vegetation with Tecoma arequipensis or "cahuato" (Schino mollis-Tecometum arequipensis), 2- Thermotropical arid plant communities with Browningia candelaris or candelabra cactus (Weberbauerocereo weberbaueri-Browningietum candelaris), 3-Mesotropical arid plant communities with Corryocactus brevistylus (Weberbauerocereo weberbaueri-Corryocactetum brevistyli), 4- Supratropical semiarid plant community with Oreocereus hendriksenianus and Corryocactus brevistylus, 5-Supratropical semiarid-dry matorrals or "tolares" (Diplostephio tacorensis-Parastrephietum lepidophyllae), 6- Orotropical dry-suhumid grasslands with matorrals or "pajonal-tolares" (Parastrephio lucidae-Festucetum orthophyllae), 7- Orotropical semiarid-dry forests or "queñuales" (Chuquirago rotundifoliae-Polylepidetum rugulosae), 8- Oro-cryorotropical rocky ground vegetation complex [Parastrephio lucidae-Festucetum orthophyllae azorelletosum compactae (static stones), Nototricho obcuneatae-Xenophylletum poposi (mobile stones)].

Harms, Chersodoma arequipensis (Cuatrec.) Cuatrec., Corryocactus aureus (Meyen) Hutchison, C. puquiensis Rauh \& Backeb., Diplostephium tacorense Hieron., D. tovari Cuatrec., Echinopsis pamparuizii Cárdenas, Fabiana stephanii Hunz. \& Barboza, Junellia arequipense (Botta) Botta, Lobivia pampana Britton \& Rose, Malesherbia ardens J.F.
Macbr., Nolana chapiensis M.O. Dillon \& Quip., Opuntia corotilla K. Schum. ex Vaupel, Oreocereus hendriksenianus Backeb., $O$. tacnaensis F. Ritter, Senecio phylloleptus Cuatrec., S. yurensis Rusby, Tecoma fulva subsp. arequipensis (Sprague) J.R.I. Wood, Weberbauerocereus rahuii Backeb., W. torataensis F. Ritter. 


\begin{tabular}{|c|c|c|c|c|}
\hline $\begin{array}{l}\text { Piso bioclimático y } \\
\text { ombroclima }\end{array}$ & $\begin{array}{c}\text { Intervalo } \\
\text { altitudinal } \\
\text { aproximado } \\
\text { (m) }\end{array}$ & Bioindicadores & $\begin{array}{c}\text { Nomenclatura } \\
\text { indígena } \\
\text { (lengua) }\end{array}$ & Uso tradicional \\
\hline $\begin{array}{l}\text { Termotropical } \\
\text { hiperárido }\end{array}$ & $0-1000$ & Tillandsia purpurea & $\begin{array}{c}\text { Chala } \\
\text { (aymara) }\end{array}$ & $\begin{array}{l}\text { Cultivos de } \\
\text { regadío }\end{array}$ \\
\hline $\begin{array}{l}\text { Termotropical } \\
\text { ultrahiperárido }\end{array}$ & $1000-2000$ & Desierto abiótico & $\begin{array}{l}\text { Yunga } \\
\text { (aymara) }\end{array}$ & $\begin{array}{l}\text { Cultivos de regadío y } \\
\text { frutales en quebradas }\end{array}$ \\
\hline $\begin{array}{l}\text { Termotropical } \\
\text { árido }\end{array}$ & $2000-2100$ & Neoraimondia arequipensis & $\begin{array}{l}\text { Yunga } \\
\text { (aymara) }\end{array}$ & $\begin{array}{l}\text { Cultivos de regadío y } \\
\text { frutales en quebradas }\end{array}$ \\
\hline $\begin{array}{l}\text { Mesotropical } \\
\text { árido-semiárido }\end{array}$ & $2100-3100$ & $\begin{array}{l}\text { Armatocereus riomajensis } \\
\text { Corryocactus aureus } \\
\text { Euphorbia apurimacensis }\end{array}$ & $\begin{array}{l}\text { Yunga } \\
\text { (aymara) }\end{array}$ & $\begin{array}{c}\text { Cultivos de regadío y } \\
\text { frutales en quebradas } \\
\text { y andenes }\end{array}$ \\
\hline $\begin{array}{c}\text { Supratropical } \\
\text { semiárido-seco }\end{array}$ & $3100-3800$ & $\begin{array}{c}\text { Cantua buxifolia } \\
\text { Diplostephium tacorense } \\
\text { Puya densiflora }\end{array}$ & $\begin{array}{c}\text { Quechua } \\
\text { (runa-shimi) }\end{array}$ & $\begin{array}{l}\text { Cultivo de tubérculos } \\
\text { y cereales en andenes }\end{array}$ \\
\hline $\begin{array}{c}\text { Orotropical } \\
\text { seco-subhúmedo }\end{array}$ & $3800-4800$ & $\begin{array}{c}\text { Festuca orthophylla } \\
\text { Parastrephia quadrangulare }\end{array}$ & $\begin{array}{c}\text { Puna } \\
\text { (runa-shimi) }\end{array}$ & $\begin{array}{l}\text { Cultivo de tubérculos } \\
\text { y cereales en andenes } \\
\text { y ganadería de } \\
\text { camélidos }\end{array}$ \\
\hline $\begin{array}{c}\text { Criorotropical } \\
\text { Seco-subhúmedo }\end{array}$ & $4800-6380$ & $\begin{array}{l}\text { Nototriche obcuneata } \\
\text { Xenophyllum poposum }\end{array}$ & $\begin{array}{c}\text { Janca } \\
\text { (runa-shimi) }\end{array}$ & $\begin{array}{c}\text { Aprovechamiento } \\
\text { de morrenas para } \\
\text { construir lagunas } \\
\text { para riego; extracción } \\
\text { de hielo para } \\
\text { consumo y anestesia }\end{array}$ \\
\hline
\end{tabular}

Tabla 2. Descripción bioclimática de los departamentos de Arequipa, Moquegua y Tacna con sus intervalos, plantas indicadoras, nombres vernáculos y usos tradicionales del suelo. Bioclimatic description of Arequipa, Moquegua and Tacna departments, with altitudinal intervals, indicative plants, vernacular names and land traditional uses.

\section{RESULTADOS Y DISCUSIÓN}

\section{Novedades fitosociológicas}

A los sintáxones ya publicados sobre el $\mathrm{S}$ del Perú (Galán de Mera et al., 2002a, 2002b, 2003a; Galán de Mera \& Vicente Orellana, 1996; Galán de Mera \& Gómez Carrión, 2001, 2003), añadimos estos nuevos (de Tecometum fulvae Galán de Mera 1996 incluimos inventarios no publicados) ordenados desde el piso termoal orotropical por formaciones vegetales.
En la figura 2, representamos un esquema de la vegetación desde Uchumayo hasta las cumbres del complejo volcánico del Chachani, sintetizando así la vegetación andina occidental del departamento de Arequipa.

\section{A. Piso termotropical}

1. Las arbustedas y bosques climatófilos de la costa

(Clase Carico candicantis-Caesalpinietea spinosae) 
Tabla 3

\begin{tabular}{|c|c|c|c|c|c|c|c|}
\hline (Carico-C & $\begin{array}{l}\text { psio } c \\
\text { tares, } \\
\text { munid } \\
\text { Cithat }\end{array}$ & $\begin{array}{l}\text { ensis } \\
\text { upos \& } \\
\text { le Cae } \\
\text { lo-Crc }\end{array}$ & $\begin{array}{l}\text { ndiet } \\
\text { cente } \\
\text { pinia } \\
\text { etalia }\end{array}$ & $\begin{array}{l}\text { rmata } \\
\text { nova } \\
\text { osa } \\
\text { indeli }\end{array}$ & lutino & & \\
\hline Inventario $\mathrm{n}^{\mathrm{o}}$ & 1 & 2 & 3 & 4 & 5 & 6 & 7 \\
\hline Área m² & 100 & 200 & 100 & 200 & 50 & 50 & 100 \\
\hline Altitud (m) & 653 & 857 & 852 & 836 & 410 & 750 & 310 \\
\hline Pendiente $(\%)$ & 30 & 50 & 10 & 30 & 10 & 10 & - \\
\hline Características de asocia & & & & & & & \\
\hline Randia armata & 4 & 4 & 4 & 4 & . & . & . \\
\hline Echinopsis chalaensis & 1 & 1 & 1 & 1 & . & . & . \\
\hline Grindelia glutinosa & 1 & . & + & + & . & . & . \\
\hline Stipa pachypus & . & 1 & 1 & . & . & . & . \\
\hline Opuntia unguispina & . & + & . & . & . & . & . \\
\hline Características de orden & & & & & & & \\
\hline Caesalpinia spinosa & 1 & 1 & 2 & 1 & 1 & 4 & . \\
\hline Carica candicans & . & . & . & . & 1 & 1 & 1 \\
\hline Croton alnifolius & + & . & . & . & . & + & . \\
\hline Capparis prisca & . & . & . & . & 1 & 1 & + \\
\hline Trixis cacalioides & 1 & . & . & . & . & . & . \\
\hline Citharexylum flexuosum & . & . & + & . & . & . & . \\
\hline Dicliptera ruiziana & . & . & . & . & . & . & 2 \\
\hline Compañeras & & & & & & & \\
\hline Nicotiana paniculata & . & . & . & + & 4 & 2 & . \\
\hline Heliotropium arborescens & . & 1 & + & . & . & . & . \\
\hline Siegesbeckia flosculosa & . & . & . & . & 3 & 2 & . \\
\hline Minthostachys mollis & . & 1 & . & . & . & . & . \\
\hline Senecio mollendoensis & . & . & + & . & . & . & . \\
\hline Hyptis sidifolia & . & . & . & . & . & . & 4 \\
\hline
\end{tabular}

Localidades: 1-4- Arequipa, lomas de Atiquipa [1- 18L 0567185, 825607; 2- 18L 0566985, 8257116; 3- 18L 0566940, 8257223; 4- 18L 0566901, 8257327]; 5-7- Lima, lomas de Huaral [18L 0254667, 8731517].

Echinopsio chalaensis-Randietum armatae Galán de Mera, Linares, Campos \& Vicente Orellana ass. nova

[Tabla 3, holotypus ass. inv. 3]

Vegetación arbustiva con cactáceas, termotropical semiárida que se asienta en las pendientes graníticas de las lomas de Atiquipa sobre suelos profundos y arenosos en superficie. Esta orientada al NE, a la avenida de las nieblas y la humedad del Océano Pacífico, que deja lluvias hasta bien entrado el mes de diciembre, llegando a crear localmente un ombroclima semiárido.

La asociación está caracterizada por tres plantas de distribución muy localizada (Ritter, 1981): Echinopsis chalaensis, Opuntia unguispina Backeb. y Randia armata (Sw.) DC. $R$. armata relaciona a este tipo de comunidades más húmedas del Desierto Pacífico con las de los bosques secos del N del Perú, donde esta especie se hace frecuente (Linares-Palomino et al., 2003).

En la tabla 3 también incluimos algunos inventarios realizados en las lomas de Huaral, al $\mathrm{N}$ de Lima, donde podemos encontrar 
comunidades de Caesalpinia spinosa con ciertas especies arbóreas o arbustivas (Capparis prisca J.F. Macbr., Carica candicans A. Gray, Dicliptera ruiziana Wassh.) que tienen una amplia distribución a lo largo de la provincia Limeño-Ariqueña, y alcanzan las laderas más secas de los Andes occidentales hasta unos 3000 m (Weberbauer, 1936).

\section{Caesalpinio spinosae-Myrcianthetum ferreyrae Galán de Mera, Linares, Campos \& Vicente Orellana ass. nova \\ [Tabla 4, holotypus ass. inv. 1]}

Los bosques con Myrcianthes ferreyrae han sido estudiados y citados por numerosos autores por su originalidad (Ferreyra, 1953, 1960, 1983; Hueck, 1966; Rundel et al., 1991), sin embargo no están incluidos en el estudio de bosques secos tropicales de Linares-Palomino et al. (2003) a pesar de presentar fisionomía y especies comunes.

Se trata de bosques termotropicales sobre suelos silíceos, donde Myrcianthes ferreyrae se hace dominante ocupando los lugares, con exposición $\mathrm{SO}$, con mayor humedad de las lomas de Atiquipa, donde se alcanza el ombroclima seco. La asociación presenta como características Citharexylum flexuosum (Ruiz \& Pav.) D. Don, Myrcianthes ferreyrae y Randia armata.

Este bosque tan localizado guarda relación con las comunidades de Myrcianthes minimifolia (McVaugh) McVaugh (Arequipa, Huancavelica) y M. coquimbensis (Barnéoud) Landrum \& Grifo, situados en Chile en los alrededores de La Serena (McVaugh, 1963; Rundel et al., 1991), pero no con los andinos de Tristerido peruviani-Myrcianthetum quinquelobae Galán de Mera \& Rosa in Galán de Mera, Rosa \& Cáceres 2002 (2500-2630 m), que presentan una combinación florística muy diferente (Galán de Mera et al., 2002b).

Grindelion glutinosae all. nova, Citharexylo

\section{flexuosi-Crotonetalia alnifolii ordo novo, Carico candicantis-Caesalpinietea spinosae cl. nova}

Incluimos tanto a Echinopsio-Randietum como a Caesalpinio-Myrcianthetum en la nueva alianza Grindelion glutinosae Galán de Mera, Linares, Campos \& Vicente Orellana all. nova del sector Arequipeño (holotypus: Caesalpinio spinosae-Myrcianthetum ferreyrae Galán de Mera, Linares, Campos \& Vicente Orellana ass. nova; características: Grindelia glutinosa (Cav.) C. Mart., Stipa pachypus Pilg.). Algunas especies de la combinación florística de estas dos nuevas asociaciones alcanzan áreas elevadas de los Andes, como Carica candicans (3000 m); otras como Citharexylum flexuosum y Croton alnifolius Lam. se quedan en las lomas costaneras y nos permiten describir el orden Citharexylo flexuosi-Crotonetalia alnifolii Galán de Mera, Linares, Campos \& Vicente Orellana ordo novo (holotypus: Grindelion glutinosae Galán de Mera, Linares, Campos \& Vicente Orellana all. nova; características: Citharexylum flexuosum, Croton alnifolius).

Este nuevo orden pertenece a la clase Carico candicantis-Caesalpinietea spinosae Galán de Mera, Linares, Campos \& Vicente Orellana cl. nova (holotypus: Citharexylo flexuosi-Crotonetalia alnifolii Galán de Mera, Linares, Campos \& Vicente Orellana ordo novo; características: Caesalpinia spinosa, Capparis prisca, Carica candicans, Dicliptera ruiziana, Trixis cacalioides (Kunth) D. Don), que reúne a los bosques y arbustedas termomesotropicales seco-semiáridos de las lomas costeras del Desierto Pacífico de la provincia Limeño-Ariqueña y de las laderas occidentales andinas de las provincias Ancashino-Paceña y Oruro-Arequipeña.

La asociación Caricetum candicantis (Galán de Mera et al., 2004) de los Andes occidentales del departamento de Lima hay que traerla a esta clase; su composición florística (Byttneria cordata Lam., Carica candicans, 
Tabla 4

\section{Caesalpinio spinosae-Myrcianthetum ferreyrae}

Galán, Linares, Campos \& Vicente ass. nova (Carico-Caesalpinietea, Citharexylo-Crotonetalia, Grindelion glutinosae)

\begin{tabular}{|c|c|c|c|c|c|c|c|c|c|}
\hline Inventario $\mathrm{n}^{\mathrm{O}}$ & 1 & 2 & 3 & 4 & 5 & 6 & 7 & 8 & 9 \\
\hline Área $\mathrm{m}^{2}$ & 200 & 200 & 200 & 200 & 200 & 100 & 200 & 400 & 200 \\
\hline Altitud (m) & 852 & 852 & 559 & 562 & 562 & 572 & 579 & 558 & 579 \\
\hline Pendiente $(\%)$ & 40 & 40 & 50 & 55 & 50 & 60 & 60 & 60 & 55 \\
\hline \multicolumn{10}{|c|}{ Características de asociación y de alianza } \\
\hline Myrcianthes ferreyrae & 2 & 3 & 2 & 2 & 3 & 3 & 3 & 2 & 2 \\
\hline Citharexylum flexuosum & 1 & 1 & + & 1 & + & . & + & 1 & 1 \\
\hline Randia armata & 3 & 1 & . & . & . & . & . & . & . \\
\hline Grindelia glutinosa & + & 1 & 3 & 2 & 2 & 2 & 1 & 3 & 3 \\
\hline Stipa pachypus & 2 & . & . & . & . & . & . & . & . \\
\hline \multicolumn{10}{|c|}{ Características de orden y clase } \\
\hline Croton alnifolius & & & 1 & 1 & 1 & 1 & 1 & 1 & 1 \\
\hline Caesalpinia spinosa & 1 & 3 & + & . & 2 & . & . & + & . \\
\hline Carica candicans & . & . & . & + & + & . & . & . & . \\
\hline Dicliptera ruiziana & . & . & . & . & . & + & . & 1 & . \\
\hline \multicolumn{10}{|l|}{ Compañeras } \\
\hline Nicotiana paniculata & . & 1 & . & + & . & . & 1 & . & 1 \\
\hline Heliotropium arborescens & 1 & 1 & . & . & . & . & . & . & . \\
\hline Acacia macracantha & & . & + & . & + & . & . & . & . \\
\hline Senecio mollendoensis & 1 & & . & . & . & . & . & . & . \\
\hline Croton ruizianus & . & 2 & . & . & . & . & . & . & . \\
\hline
\end{tabular}

Localidades: 1-9- Arequipa, lomas de Atiquipa [1- 18L 0566901, 8257327; 2- 18L 0566896, 8257362; 318L 0571518, 8254891; 4- 18L 0571455, 8254872; 5- 18L 0571413, 8254833; 6- 18L 0571428, 8254584; 7- 18L 0571399, 8254548; 8- 18L 0571378, 8254461; 9- 18L 0571360, 8254405].

Echinopsis pachanoi (Britton \& Rose) Friedrich \& G.D. Rowley) sugiere otro nuevo orden aún por describir.

2. La vegetación herbácea de las lomas costaneras

(Clase Palauo dissectae-Nolanetea gayanae)

\section{Nolano spathulatae-Palauetum dissectae}

Galán de Mera, Linares, Campos \& Vicente Orellana ass. nova

[Tabla 5, holotypus ass. inv. 2]

Vegetación terofítica termotropical árida con floración muy vistosa que, de noviembre a marzo, tapiza las lomas costeras del Desierto Pacífico, con orientación SO sobre suelos arenosos poco estabilizados resultantes de aportes eólicos, hasta una altitud de unos 200 m. Es una asociación que se extiende desde Arequipa a Tacna y es muy rica en endemismos, entre los que podemos destacar Lupinus mollendoensis Ulbr., Nolana pallidula, $N$. spathulata y Weberbauerella brongniartioides (el género es endémico del sector Arequipeño). Son además característicos otros endemismos que no están presentes en la tabla 5, como Malesherbia angustisecta Harms, Nolana plicata I.M. Johnst. y N. tomentella Ferreyra.

Nolano-Palauetum es vicariante de Tetragonio crystallinae- Nolanetum humifusae Müller 1985, descrita en las cercanías de Lima.

\section{Hoffmannseggio mirandae-Palauetum weberbaueri Galán de Mera, Linares, Campos \& Vicente Orellana ass. nova}


Tabla 5

1-8: Nolano spathulatae-Palauetum dissectae Galán, Linares, Campos \& Vicente

9-13: Hoffmannseggio mirandae-Palauetum weberbaueri Galán, Linares, Campos \& Vicente (Palauo-Nolanetea, Commelinetalia, Loasion)

\begin{tabular}{lccccccccccccc}
\hline Inventario $^{\circ}$ & 1 & 2 & 3 & 4 & 5 & 6 & 7 & 8 & 9 & 10 & 11 & 12 & 13 \\
Área $\left(\mathrm{m}^{2}\right)$ & 100 & 100 & 100 & 100 & 100 & 100 & 100 & 100 & 100 & 100 & 100 & 100 & 100 \\
Altitud $(\mathrm{m})$ & 200 & 224 & 225 & 224 & 224 & 225 & 225 & 225 & 330 & 336 & 340 & 340 & 340 \\
Pendiente (\%) & 40 & 45 & 40 & 30 & 40 & 40 & 30 & 10 & 20 & 10 & 20 & 10 & 5
\end{tabular}

Características de asociación y alianza

Nolana spathulata

Palaua velutina

Weberbauerella brongniartioides

Lupinus mollendoensis

Nolana pallidula

Palaua weberbaueri

Spergularia congestifolia

Hoffmannseggia miranda

Loasa urens

Características de orden y clase

Leptoglossis lomana

Palaua dissecta

Eragrostis nigricans

Hoffmannseggia postrata

Eragrostis weberbaueri

Cenchrus brownii

Plantago limensis

Monnina macrostachya

Cistanthe paniculata

Oenothera arequipensis

Onoseris odorata

Nothoscordum bivalve

Nolana humifusa

Linaria canadensis

\section{Compañeras}

Grindelia glutinosa

Encelia canescens

Rubiaceae

Chenopodium petiolare

Sonchus oleraceus

Portulaca perennis

Gamochaeta purpurea

Localidades: 1-13- Arequipa, lomas de Mejía [1- 19K 0191893, 8107849; 2- 19K 0191903, 8107853; 3- 19K 0192035, 8107927; 4- 19K 0192245, 8107813; 5- 19K 0192295, 8107815; 6- 19K 0192315, 8107789; 719K 0191843, 8108197; 8- 19K 0191704, 8108327; 9- 19K 0192335, 8108129; 10- 19K 0192337, 8108168; 11- 19K 0192360, 8108179; 12- 19K 0192407, 8108177; 13- 19K 0192232, 8108304]. 


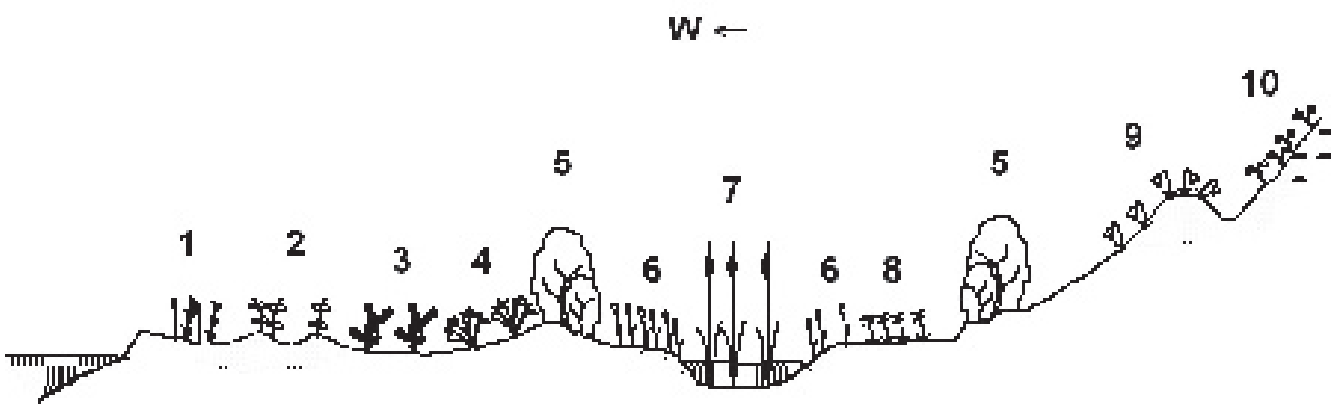

Figura 3. Esquema de la vegetación en la costa de Mejía (departamento de Arequipa). 1- Pastizal costero (Sporobolo virginici-Distichlietum spicatae), 2- Vegetación de suelos arenosos salinos (Cresso truxillensis-Distichlietum spicatae), 3- Asociación de suelos salinos profundos con inundación intermitente (Sarcocornietum neei), 4- Vegetación de suelos salinos húmedos no inundables (Cypero laevigatiDistichlietum spicatae), 5- Arbustedas halófilas (Plucheetum absinthioidis), 6- Juncales (Schoenoplectetum olneyi-americani), 7- Vegetación de grandes helófitos o "totorales" (Bacopo monnieri-Typhetum domingenis), 8- Gramadales inundados por aguas salobres (Lippio nodiflorae-Paspaletum vaginati), 9- Herbazales de las lomas sobre suelos arenosos poco estabilizados (Nolano spathulatae-Palauetum dissectae), 10- Herbazales de las lomas sobre suelos arenosos estabilizados (Hoffmannseggio mirandae-Palauetum weberbaueri). Vegetation scheme of the Mejia coast (Arequipa Department). 1-Coastal grassland (Sporobolo virginiciDistichlietum spicatae), 2- Vegetation on sandy and salt soils (Cresso truxillensis-Distichlietum spicatae), 3- Association of salt deep soils intermittently flooded (Sarcocornietum neei), 4- Vegetation on humid salt soils no flooded (Cypero laevigati-Distichlietum spicatae), 5- Halophilous schrub communities (Plucheetum absinthioidis), 6-Rushes (Schoenoplectetum olneyi-americani), 7-Tall halophytic vegetation or "totorales" (Bacopo monnieri-Typhetum domingensis), 8- Grassland flooded by salt waters (Lippio nodiflorae-Paspaletum vaginati), 9- Herbs on low stabilized sandy soils (Nolano spathulatae-Palauetum dissectae), 10- Herbs on stabilized sandy soils (Hoffmannseggio mirandae-Palauetum weberbaueri).

[Tabla 5, holotypus ass. inv. 10]

Esta asociación, también del sector Arequipeño, se diferencia de la anterior porque se instala sobre arenas consolidadas a mayor altitud (300-400 m), como demuestra la presencia de algunas plantas vivaces, como Hoffmannseggia miranda Sandwith, Nothoscordum bivalve (L.) Britton o Spergularia congestifolia I.M. Johnst., mostrándose vicariante de Palauo rhombifoliae-Nolanetum gayanae Müller 1985 de las lomas del centro.

Las lomas costeras del Desierto Pacífico han sido estudiadas por numerosos autores tanto en Chile (Johnston, 1929; Rundel et al., 1991) como en Perú (Bruns, 1929; Ellenberg, 1959; Ferreyra, 1953, 1960, 1983; Müller 1985a, 1985b, 1988). Forman isleos de vegetación a lo largo de un desierto muy árido, por lo que la diversidad de endemismos es muy elevada (Galán de Mera et al., 1997). En un trabajo anterior (Galán de Mera et al., 2002b) propusimos la alianza Loasion urentis Galán de Mera \& Rosa in Galán de Mera, Rosa \& Cáceres 2002 dentro del orden Commelinetalia fasciculatae Galán de Mera \& Rosa in Galán de Mera, Rosa \& Cáceres 2002 (Palauo dissectaeNolanetea gayanae Galán de Mera 2005) que reúne a las comunidades efímeras de lomas.

3. La vegetación de los saladares de la costa (fig. 3)

(Clase Batido-Sarcocornietea ambiguae)

Sporobolo virginici-Distichlietum spicatae Galán de Mera, Linares, Campos \& Vicente Orellana ass. nova

[Tabla 6, holotypus ass. inv. 3]

Gramadal psamófilo costero neotropical 
Tabla 6

1-7: Sporobolo virginici-Distichlietum spicatae Galán, Linares, Campos \& Vicente ass. nova

8-12: Cresso truxillensis-Distichlietum spicatae Galán, Linares, Campos \& Vicente ass. nova

13-18: Cypero laevigati-Distichlietum spicatae Galán, Linares, Campos \& Vicente ass. nova

(Batido-Sarcocornietea, Sarcocornietalia neei, Sarcocornion-Distichlion)

\begin{tabular}{|c|c|c|c|c|c|c|c|c|c|c|c|c|c|c|c|c|c|c|}
\hline Inventario $\mathrm{n}^{\mathrm{O}}$ & 1 & 2 & 3 & 4 & 5 & 6 & 7 & 8 & 9 & 10 & 11 & 12 & 13 & 14 & 15 & 16 & 17 & 18 \\
\hline Área (Dm) & 5 & 10 & 10 & 10 & 10 & - & - & 10 & 10 & 5 & 2 & 2 & 5 & 5 & 5 & 5 & 10 & - \\
\hline \multicolumn{19}{|c|}{ Características de asociación y alianza } \\
\hline Sporobolus virginicus & 2 & 1 & 4 & 4 & 3 & 3 & 5 & . & . & . & . & & . & . & . & . & & \\
\hline Cressa truxillensis & . & . & . & . & . & . & . & 1 & 1 & 1 & 2 & 5 & . & . & . & . & & \\
\hline Cyperus laevigatus & . & . & . & . & . & . & . & . & . & . & . & . & 2 & 2 & . & 1 & 1 & 1 \\
\hline \multicolumn{19}{|l|}{ Bacopa monnieri (DC) } \\
\hline Bacopa monnieri & . & & . & . & . & . & . & . & . & . & . & . & . & . & 1 & 5 & 5 & 4 \\
\hline \multicolumn{19}{|c|}{ Características de orden y clase } \\
\hline Distichlis spicata & 5 & 4 & 1 & 1 & 1 & . & . & 5 & 1 & 1 & + & + & 5 & 5 & 5 & 1 & & 1 \\
\hline Sarcocornia neei & + & . & . & . & . & . & . & 1 & . & . & . & + & . & . & . & . & & . \\
\hline Heliotropium curassavicum & . & . & . & . & . & . & . & . & . & . & . & . & + & . & + & + & & . \\
\hline \multicolumn{19}{|l|}{ Compañeras } \\
\hline Portulaca oleracea & . & . & . & . & . & . & . & . & . & . & . & & + & . & . & . & 3 & \\
\hline Lippia nodiflora & . & . & . & . & . & . & . & . & . & . & . & . & . & 2 & . & . & & \\
\hline Grindelia glutinosa & . & . & . & . & . & . & . & . & . & . & . & . & $\cdot$ & $\cdot$ & + & . & & \\
\hline Plantago rigida & . & . & . & . & . & . & . & . & . & . & . & . & . & . & . & . & & 2 \\
\hline Scirpus pungens & . & . & . & . & . & . & . & . & . & . & . & . & . & . & . & . & & 1 \\
\hline Samolus valerandi & . & . & . & . & . & . & . & . & . & . & . & . & . & . & . & . & & 1 \\
\hline Paspalum vaginatum & . & . & . & . & . & . & . & . & . & . & . & . & . & . & . & . & & 1 \\
\hline Jussieua repens & . & . & . & . & & . & . & . & . & 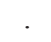 & . & 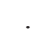 & 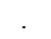 & . & . & . & & 1 \\
\hline
\end{tabular}

Localidades: 1 y 12- Arequipa, Camaná, La Punta [1- 18K 0747355, 8157041]; 2-5, 8-11, 17- Arequipa, lagunas de Mejía [2- 19K 0193859, 8102878; 3- 19K 0194206, 8102543; 4- 19K 0194601, 8102209; 5- 19K 0195271, 8101491; 8- 19K 0193328, 8104094; 9- 19K 0193576, 8103843; 10- 19K 0193971, 8103546; 11- 19K 0194490, 8103129; 17- 19K 0192333, 8104867]; 6 y 7- Lima, lagunas de Conchán (López Guillén \& Rivas Goday, 1952: 607); 18- Lima, lagunas de Conchán (López Guillén \& Rivas Goday, 1952: 609); 13 16- Tacna, quebrada de Sama [13- 19K 0305818, 8005779; 14- 19K 0305944, 8005860; 15- 19K 0305979, 8005874; 16- 19K 0305965, 800585].

que soporta muy poca humedad, limitando con el desierto litoral (López Guillén \& Rivas Goday, 1952). Sus especies características son Sporobolus virginicus (L.) Kunth y Distichlis spicata (L.) Greene.

\section{Cresso truxillensis-Distichlietum spicatae}

Galán de Mera, Linares, Campos \& Vicente Orellana ass. nova

[Tabla 6, holotypus ass. inv. 12]

Asociación limeño-ariqueña propia de suelos muy arenosos que llegan a formar dunas. Las especies características son Cressa truxillensis Kunth y Distichlis spicata. Sobre el paralelo $8^{\circ}$ es sustituida por las comunidades de dunas de la alianza Ipomoeo-Canavalion (Borhidi et al., 1979) cuyas características en el Perú son: Canavalia rosea (Sw.) DC., Ipomoea alba L., I. pes-caprae (L.) R. Br. y Lycium americanum Jacq.

Cypero laevigati-Distichlietum spicatae Galán de Mera, Linares, Campos \& Vicente Orellana ass. nova

[Tabla 6, holotypus ass. inv. 13]

Es una asociación también limeño-ariqueña 
Tabla 7

1-11: Lippio nodiflorae-Paspaletum vaginati Galán, Linares, Campos \& Vicente ass. nova 12-18: schoenoplectetosum olneyi Galán, Linares, Campos \& Vicente subass. nova (Xyrido-Typhetea, Schoenoplectetalia, Ludwigio-Paspalion)

\begin{tabular}{|c|c|c|c|c|c|c|c|c|c|c|c|c|c|c|c|c|c|c|}
\hline Inventario $\mathrm{n}^{\mathrm{o}}$ & 1 & 2 & 3 & 4 & 5 & 6 & 7 & 8 & 9 & 10 & 11 & & 13 & & 15 & & 171 & 18 \\
\hline Área $\left(m^{2}\right)$ & 20 & 20 & 10 & 4 & 4 & 20 & 50 & 20 & 5 & 20 & - & & 20 & & 20 & 202 & & - \\
\hline Profundidad $(\mathrm{cm})$ & 20 & 40 & 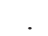 & . & & . & . & . & . & . & & & 100 & & . & & 100 & \\
\hline \multicolumn{19}{|c|}{ Características de asociación y alianza } \\
\hline Paspalum vaginatum & 5 & 5 & 5 & + & 2 & 2 & 5 & 5 & 2 & 1 & 4 & 5 & 5 & 5 & 5 & 5 & 5 & $\mathrm{~V}$ \\
\hline Lippia nodiflora & 1 & . & . & 4 & 4 & 5 & 1 & 3 & . & . & . & . & . & . & . & . & & II \\
\hline Ludwigia octovalvis & . & . & . & . & . & . & . & . & 4 & 5 & . & . & . & . & . & . & & . \\
\hline \multicolumn{19}{|l|}{ Diferencial de subasociación } \\
\hline Schoenoplectus olneyi & . & . & . & . & & . & . & . & . & & . & 1 & 1 & 2 & 1 & 2 & & IV \\
\hline \multicolumn{19}{|c|}{ Características de orden y clase } \\
\hline Ludwigia pubescens & . & . & . & . & . & . & . & . & 1 & 1 & & . & . & . & . & . & & + \\
\hline Hydrocotyle bonariensis & . & . & . & . & . & . & 2 & . & . & . & 2 & . & . & . & . & . & & I \\
\hline Typha domingens & . & + & . & . & . & . & . & . & . & . & . & . & . & . & . & . & & . \\
\hline Phragmites australis & . & . & . & . & . & . & . & . & . & . & 1 & . & . & . & . & . & & . \\
\hline Eleocharis caribaea & . & . & . & . & . & . & . & . & . & . & . & . & . & . & . & . & & + \\
\hline \multicolumn{19}{|l|}{ Compañeras } \\
\hline Heliotropium cura & . & . & 1 & 2 & 1 & 1 & . & . & . & . & + & . & . & . & . & 2 & & I \\
\hline Bacopa monnieri & . & . & . & • & $\cdot$ & . & . & . & . & . & + & . & . & 2 & 4 & . & & II \\
\hline Chenopodium ambrosioides & . & . & . & 1 & 2 & 2 & . & . & . & . & . & . & . & . & . & . & & . \\
\hline Tessaria absinthioides & 1 & 1 & . & . & . & . & . & + & . & . & . & . & . & . & . & . & & . \\
\hline Sporobolus virginicus & . & . & . & . & . & . & . & . & . & . & 2 & . & . & 1 & . & . & & . \\
\hline
\end{tabular}

Otras plantas: Ricinus communis + , Cressa truxillensis + , Spilanthes oleracea 1 en 8; Plantago major 1 en 10; Clorofíceas + en 12; Portulaca oleracea 1 en 16; Apium graveolens + , Cyperus laevigatus II, Triglochin striata I, Sesuvium portulacastrum +, Salomus valerandi + en 18.

Localidades: 1-3, 12 y 13, 15, 16- Arequipa: Quilca, quebrada de Platanal [1-18K 0774978, 8149491; 2- 18K 0774710, 8149777; 3- 18K 0774873, 8149747; 12- 18K 0774712, 8149564; 13- 18K 0774650, 8149486; 15-18K 0746133, 8157947; 16- 18K 07748661, 8149456]; 4-10 y 14, 17- Arequipa: Camaná, arrozales de la Punta [4- 18K 0745337, 8158171; 5- 18K 0745336, 8158102; 6- 18K 0745332, 8157793; 7- 18K 0745627, 8158108; 8- 18K 0745815, 8157857; 9- 18K 0745814, 8157857; 10- 18K 0746342, 8157623; 14- 18K 0746111, 8158049; 17- 18K 0774861, 8149456]; 11- Lima: Lima, Barranco (Müller \& Gutte, 1985: 418); 18- Lima: Villa, Lurín, Chilca (Müller \& Gutte, 1983: 508, tab. 4).

que ya fue inventariada por López Guillén \& Rivas Goday (1952) sobre suelos húmedos, como demuestran su especie característica (Cyperus laevigatus L.), pero que no llegan a encharcarse. La acción antrópica sobre esta fitocenosis conduce a una comunidad derivada (DC), en el sentido de Kopecký et al. (1995), donde Bacopa monnieri se hace dominante (inventarios 15-18).

Sarcocornio neei-Distichlion spicatae all. nova, Sarcocornietalia neei ordo novo
La aclaración taxonómica del género Sarcocornia A.J. Scott en América del Sur (Müller \& Gutte, 1983; Alonso \& Crespo, 2008) nos facilita la construcción del esquema sintaxonómico de las áreas salinas de la costa del S de Ecuador y Perú, hasta el centro-sur de Chile. Podemos incluir la vegetación de los saladares de la costa peruana en la nueva alianza Sarcocornio neei-Distichlion spicatae Galán de Mera, Linares, Campos \& Vicente Orellana all. nova (holotypus: Sarcocornietum neei Müller \& Gutte 1983, nom. mut. propos. [Salicornietum 
Tabla 8

\begin{tabular}{|c|c|c|c|c|c|c|c|c|c|c|}
\hline \multicolumn{11}{|c|}{$\begin{array}{c}\text { Schoenoplectetum olneyi-americani Galán, Linares, Campos \& Vicente ass. nova } \\
\text { (Xyrido-Typhetea, Schoenoplectetalia, Ludwigio-Paspalion) }\end{array}$} \\
\hline Inventario $\mathrm{n}^{\circ}$ & 1 & 2 & 3 & 4 & 5 & 6 & 7 & 8 & 9 & 10 \\
\hline Área $\left(\mathrm{m}^{2}\right)$ & 100 & 100 & 100 & 100 & 100 & 100 & 100 & 100 & 50 & - \\
\hline Profundidad $(\mathrm{cm})$ & - & - & - & - & - & - & 12 & 12 & - &.- \\
\hline \multicolumn{11}{|c|}{ Características de asociación y alianza } \\
\hline Schoenoplectus americanus & 5 & 5 & 5 & 5 & 5 & 5 & 5 & 5 & 4 & $\mathrm{~V}$ \\
\hline Schoenoplectus olneyi & 1 & 1 & 1 & 1 & 1 & . & . & 2 & . & . \\
\hline Paspalum vaginatum & 2 & 1 & 2 & 3 & 2 & . & 1 & . & . & IV \\
\hline Lippia nodiflora & . & . & . & . & . & . & . & . & 2 & 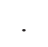 \\
\hline \multicolumn{11}{|l|}{ Características de orden y clase } \\
\hline Typha domingensis & . & . & . & . & . & . & + & + & . & II \\
\hline Hydrocotyle bonariensis & . & . & . & . & . & . & . & . & . & IV \\
\hline Eleocharis caribaea & . & . & . & . & . & . & . & . & . & I \\
\hline Vigna luteola & . & . & . & . & . & . & . & . & . & + \\
\hline Cyperus ferax & . & . & . & . & . & . & . & . & . & + \\
\hline Polypogon viridis & . & . & . & . & . & . & . & . & . & + \\
\hline Ludwigia pubescens & . & . & . & . & . & . & . & . & . & + \\
\hline \multicolumn{11}{|l|}{ Compañeras } \\
\hline Distichlis spicata & + & 1 & . & 1 & . & . & . & 2 & 1 & \\
\hline Bacopa monnieri & . & . & . & . & . & . & . & . & 1 & III \\
\hline Cressa truxillensis & . & . & . & . & . & 1 & . & . & . & . \\
\hline Althernanthera eupatorioides & . & . & . & . & . & . & . & . & 1 & . \\
\hline Phalaris canariensis & . & . & . & . & . & . & . & . & 1 & . \\
\hline Heliotropium curassavicum & . & . & . & . & . & . & . & . & + & . \\
\hline Cyperus laevigatus & . & . & . & . & . & . & . & . & . & + \\
\hline Spilanthes urens & . & . & . & . & . & . & . & . & . & + \\
\hline Plantago major & . & . & . & . & . & . & . & . & . & + \\
\hline Enhydra maritima & . & . & . & . & . & . & . & . & . & + \\
\hline
\end{tabular}

Localidades: 1-8-Arequipa: lagunas de Mejía [1- 19K 0192969, 8104162; 2- 19K 0193535, 8103992; 3- 19K 0193436, 8103632; 4- 19K 0193521, 8103661; 5- 19K 0193855, 8103557; 6- 19K 0193963, 8103210; 719K 0194187, 8103253; 8- 19K 0194436, 8102629]; 9- Tacna: quebrada de Sama [19K 0305914, 8005991]; 10- Lima: pantanos de Villa (Müller \& Gutte, 1985, tab. 6).

peruvianae]; características: Distichlis spicata, Sarcocornia neei (Lag.) M.A. Alonso \& M.B.Crespo), en el orden Sarcocornietalia neei Galán de Mera, Linares, Campos \& Vicente Orellana ordo novo (holotypus: Sarcocornio neei-Distichlion spicatae Galán de Mera, Linares, Campos \& Vicente Orellana all. nova; característica: Sarcocornia neei), vicariante del caribeño Batido-Sarcocornietalia ambiaguae Borhidi 1991 nom. mut. propos. [Batido-Salicornietalia ambiguae], y en la clase neotropical Batido-Sarcocornietea ambiguae Borhidi 1991 nom. mut. propos. [Batido-
Salicornietea ambiguae](características en el Perú: Batis maritima L., Distichlis spicata, Heliotropium curassavicum L., Suaeda foliosa Moq., Sporobolus virginicus).

Sarcocornia andina (Phil.) Freitag, M.A. Alonso \& M.B. Crespo y S. pulvinata (R.E. Fr.) A.J. Scott, de los saladares supra-orotropicales de la provincia Oruro-Arequipeña, pertenecen a la clase Distichlio humilis-Anthobryetea triandri (Navarro, 1993).

4. Los pastizales y la vegetación helofítica de la costa (fig. 3) 
(Clase Xyrido carolinianae-Typhetea domingensis)

\section{Lippio nodiflorae-Paspaletum vaginati Galán de Mera, Linares, Campos \& Vicente Orellana ass. nova \\ [Tabla 7, holotypus ass. inv. 8]}

Gramadales de aguas salobres que se extienden a lo largo de la costa pacífica (Müller \& Gutte, 1983; Tovar, 1993) ocupando grandes extensiones sobre los suelos areno-limosos de la desembocadura de los ríos que descienden de los Andes. Estos pastizales de la grama dulce (Paspalum vaginatum Sw.) se dedican al pastoreo con ovejas, vacas y caballos, y son el sustento de la ganadería de las haciendas que se distribuyen por la costa peruana. Son especies características de la asociación Lippia nodiflora (L.) Michx. y Paspalum vaginatum; se comportan como diferenciales: Bacopa monnieri, Heliotropium curassavicum e Hydrocotyle bonariensis Lam.

Sobre suelos frecuentemente inundados la asociación se enriquece con el junco de tallo triangular, Schoenoplectus olneyi (A. Gray) Palla (Linares Perea, 1997), por lo que podemos describir la subasociación schoenoplectetosum olneyi Galán de Mera, Linares, Campos \& Vicente Orellana subass. nova [tabla 7, holotypus subass. inv. 16].

Schoenoplectetum olneyi-americani Galán de Mera, Linares, Campos \& Vicente Orellana ass. nova

[Tabla 8, holotypus ass. inv. 8]

Juncales de la costa pacífica que se extienden por las provincias Pacífica y LimeñoAriqueña, siendo muy distintas florísticamente a las comunidades chilenas de la región Valdiviano-Magallánica (San Martín Padovani et al., 1993). Se caracterizan por la presencia de Schoenoplectus olneyi que, en América del Sur, se distribuye por la costa pacífica tropical (Schuyler, 1974; Sagástegui Alva \& Leiva González, 1993) y son vicariantes de la asociación Acrosticho-Schoenoplectetum americanae Borhidi in Borhidi, Muñiz \& Del Risco 1983 descrita en Cuba.

Hacia aguas más profundas Schoenoplectetum olneyi-americani contacta con los grandes helófitos de la asociación Bacopo monnieri-Typhetum domingensis Galán de Mera 1995, y hacia los suelos más secos, con las arbustedas riparias con Pluchea absinthioides (Hook. \& Arn.) H. Rob., Salix humboldtiana Willd. y Tessaria integrifolia Ruiz \& Pav.

La ausencia en la tabla 8 de características de la clase es debida a que en el S del Perú los juncales presentan una inundación menos frecuente, y por lo tanto son menos diversos.

\section{Ludwigio octovalvis-Paspalion vaginati all. nova, Schoenoplectetalia olneyi- americani ordo novo}

Los pastizales de Paspalum vaginatum y los juncales de Schoenoplectus americanus (Pers.) Volkart ex Schinz \& R. Keller presentan una combinación florística muy distinta a todo lo descrito en el $\mathrm{N}$ de América del Sur y el Caribe (Rangel \& Aguirre, 1983; Borhidi, 1996; Galán de Mera, 2007) donde los juncales quedan incluidos en el orden Scirpo-Eleocharitetalia interstinctae Borhidi 1996. Por esta razón describimos la alianza Ludwigio octovalvis-Paspalion vaginati Galán de Mera, Linares, Campos \& Vicente Orellana all. nova (holotypus: Lippio nodifloraePaspaletum vaginati Galán de Mera, Linares, Campos \& Vicente Orellana ass. nova; características: Lippia nodiflora, Ludwigia octovalvis (Jacq.) P.H. Raven, Paspalum vaginatum). Esta alianza la incluimos en el nuevo orden Schoenoplectetalia olneyiamericani Galán de Mera, Linares, Campos \& Vicente Orellana ordo novo (holotypus: Lippio nodiflorae-Paspalion vaginati Galán de Mera, 
Tabla 9

1-7: Plucheetum absinthioidis Galán, Linares, Campos \& Vicente ass. nova

8-9: Comunidad de Geoffroea decorticans

(Tessario-Baccharidetea, Tessario-Baccharidetalia, Plucheion absinthioidis)

\begin{tabular}{|c|c|c|c|c|c|c|c|c|c|}
\hline Inventario $\mathrm{n}^{\mathrm{o}}$ & 1 & 2 & 3 & 4 & 5 & 6 & 7 & 8 & 9 \\
\hline Área $\left(\mathrm{m}^{2}\right)$ & 200 & 100 & 100 & 100 & 100 & 100 & 100 & 100 & 100 \\
\hline \multicolumn{10}{|c|}{ Características de asociación y alianza } \\
\hline Pluchea absinthioides & 5 & 5 & 4 & 4 & 5 & 1 & 3 & 1 & + \\
\hline Geoffroea decorticans & . & . & . & . & . & . & . & 4 & 3 \\
\hline \multicolumn{10}{|c|}{ Características de orden y clase } \\
\hline Baccharis salicifolia & . & . & . & . & . & 1 & . & . & 2 \\
\hline \multicolumn{10}{|l|}{ Compañeras } \\
\hline Paspalum vaginatum & 2 & 2 & 2 & 1 & 2 & . & . & . & . \\
\hline Distichlis spicata & . & . & 1 & . & . & 5 & 4 & . & 1 \\
\hline Baccharis latifolia & . & . & . & . & . & 2 & 2 & . & . \\
\hline Schinus molle & . & . & . & . & . & . & . & + & 1 \\
\hline Acacia macracantha & . & . & . & . & . & . & . & 1 & 2 \\
\hline Phragmites autralis & . & . & . & + & . & . & . & . & . \\
\hline Schoenoplectus olneyi & . & . & . & . & . & . & 3 & . & . \\
\hline
\end{tabular}

Localidades: 1-3- Arequipa: Quilca, quebrada de Platanal [1- 18K 0774818, 8149466; 2- 18K 0774883, 8149615; 3- 18K 0775021, 8149382]; 4 y 5- Arequipa: lagunas de Mejía [4- 19K 0192959, 8104159; 5- 19K 0193076, 8104065]; 6-8- Tacna: quebrada de Sama [6- 19K 0323121, 7992839; 7- 19K 0323458, 7993331; 8- 19K 0323456, 7991230]; 9- Chile, Tarapacá, Iquique, puente Chaca [19K 0401134, 7837866].

Linares, Campos \& Vicente Orellana all. nova; características: Schoenoplectus americanus, $S$. olneyi). Pastizales, juncales y comunidades de grandes helófitos se incluyen en la clase neotropical Xyrido carolinianae-Typhetea domingensis O. Bolòs, Cervi \& Hatschbach 1991.

5. El monte ribereño de la costa

(Clase Tessario integrifoliaeBaccharidetea salicifoliae)

Plucheetum absinthioidis Galán de Mera, Linares, Campos \& Vicente Orellana ass. nova

[Tabla 9, holotypus ass. inv. 6]

Arbustedas del sector Arequipeño casi monoespecíficas, dominadas por Pluchea absinthioides, que se sitúan en áreas arenolimosas inundadas permanentemente por aguas las salobres de los caños y acequias de la desembocadura de los ríos andinos (fig. 3).

\section{Comunidad de Geoffroea decorticans}

[Tabla 9]

Solamente hemos podido levantar dos inventarios en bosquetes de Geoffroea decorticans (Gillies ex Hook. \& Arn.) Burkart, especie que hasta ahora no conocíamos del Perú (Brako \& Zarucchi, 1993; Solomon, 2009).

Es una comunidad de freatófitos sobre suelos salinos, que se inunda intermitentemente dejando costras poligonales. Solo conocemos esta comunidad de una localidad peruana y del $\mathrm{N}$ de Chile.

\section{Plucheion absinthioidis all. nova}

El monte ribereño de la costa del S del Perú y del $\mathrm{N}$ de Chile está caracterizado por Pluchea absinthioides, especie que no se conoce más al $\mathrm{N}$ del departamento de Arequipa (Brako 
\& Zarucchi, 1993), por lo que describimos la alianza costera Plucheion absinthioidis Galán de Mera, Linares, Campos \& Vicente Orellana all. nova (holotypus: Plucheetum absinthioidis Galán de Mera, Linares, Campos \& Vicente Orellana ass. nova; características: Geoffroea decorticans, Pluchea absinthioides). La presencia de Baccharis salicifolia (Ruiz \& Pav.) Pers. en algunos inventarios (Linares Perea, 1997) permite incluir esta alianza en el orden Plucheo absinthioidis-Baccharidetalia salicifoliae Navarro in Navarro \& Maldonado 2002 y en la clase Tessario integrifoliaeBaccharidetea salicifoliae Rivas-Martínez \& Navarro in Navarro \& Maldonado 2002.

6. Las comunidades de freatófitos de las quebradas

(Clase Acacio macracanthae-Prosopidetea pallidae)

Schino mollis-Tecometum tanaceiiflorae Galán de Mera, Linares, Campos \& Vicente Orellana ass. nova

[Tabla 10, holotypus ass. inv. 1]

Freatófitos termo-mesotropicales de las quebradas arenosas ligadas al río Colca (Chuquibamba, Ayo, Huacán y Siguas), donde el endemismo del sector Arequipeño Tecoma fulva subsp. tanaceiiflora es acompañado de otras plantas de la asociación, como Acacia macracantha Humb. \& Bonpl. ex Willd. y Schinus molle L.

\section{Acacio macracanthae-Tecometum guarumis}

Galán de Mera, Linares, Campos \& Vicente Orellana ass. nova

[Tabla 10, holotypus ass. inv. 6]

Asociación termo-mesotropical de suelos arenosos, caracterizada por Tecoma fulva subsp. guarume (DC.) J.R.I. Wood, endemismo de la Península de Ica, que se acompaña en ocasiones por otras especies de amplia distribución, como Bulnesia retama (Gillies ex Hook. \& Arn.) Griseb., Scutia spicata (Humb. \& Bonpl. ex Willd.) Weberb. y Vallesia glabra (Cav.) Link.

Schino mollis-Tecometum arequipensis Galán de Mera, Linares, Campos \& Vicente Orellana ass. nova

[Tabla 10, holotypus ass. inv. 13]

Freatófitos termo-mesotropicales que colonizan los suelos arenosos de las quebradas tributarias de los ríos Chili (Arequipa) y Tambo (Moquegua), por donde se distribuye Tecoma fulva subsp. arequipensis (Sprague) J.R.I. Wood acompañado de Schinus molle y Acacia macracantha. Este pequeño árbol, llamado localmente "cahuato", es utilizado para la confección de canastas, por lo que es frecuente encontrarlo en los linderos de los huertos.

Cuando los suelos se enriquecen en arcillas, Tecoma fulva subsp. arequipensis es sustituido por Prosopis pallida (Humb. \& Bonpl. ex Willd.) Kunth (tab. 10, inv. 17), que, junto con Baccharis latifolia, se asienta en suelos con placas poligonales y eflorescencias salinas causadas por la sequía, como se puede observar en Yarabamba, al SO de la ciudad de Arequipa. Esta situación recuerda a la de las comunidades de Prosopis tamarugo Phil. en la Pampa del Tamarugal junto a Iquique (Chile).

\section{Tecometum fulvae Galán de Mera 1996}

[Tabla 10]

A los inventarios ya publicados (Galán de Mera, 1996) añadimos esta serie del río Caplina (Tacna) y alrededores, que alcanzan el piso mesotropical hasta los $2250 \mathrm{~m}$, siempre en suelos muy arenosos. Tecoma fulva (Cav.) G. Don subsp. fulva alcanza también el N de Chile (Wood, 2008); sin embargo, en las localidades que cita este autor en el departamento de Moquegua solo hemos encontrado T. fulva subsp. arequipensis, que 

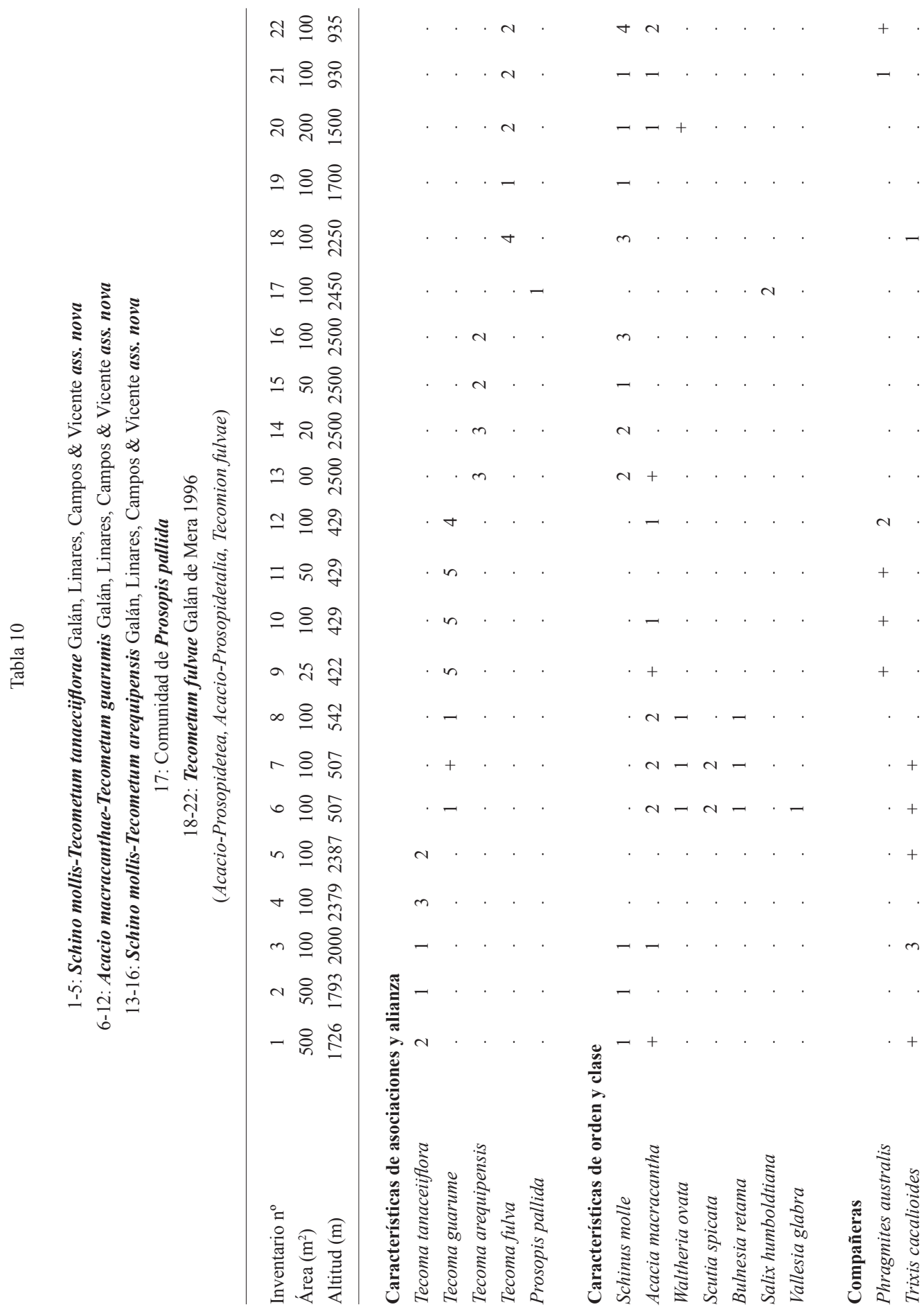


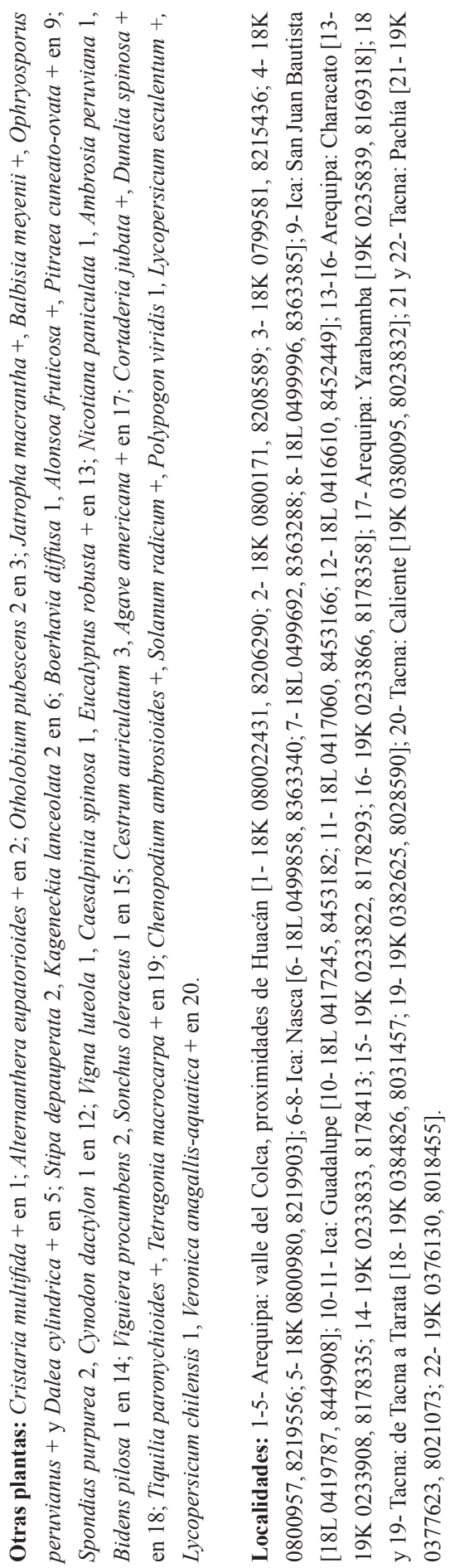


Tabla 11

Weberbauerocereo rahuii-Browningietum candelaris Galán, Linares, Campos \& Vicente ass. nova

(Opuntietea sphaericae, Oreocereo-Neoraimondietalia, Corryocaction brevistyli)

\begin{tabular}{|c|c|c|c|c|c|}
\hline Inventario $\mathrm{n}^{\mathrm{o}}$ & 1 & 2 & 3 & 4 & 5 \\
\hline Área $\left(\mathrm{m}^{2}\right)$ & 1000 & 1000 & 500 & 100 & 200 \\
\hline Altitud (m) & 2059 & 2059 & 2078 & 2140 & 2122 \\
\hline Pendiente $(\%)$ & 35 & 40 & 30 & 50 & 50 \\
\hline \multicolumn{6}{|c|}{ Características de asociación y alianza } \\
\hline Weberbauerocereus rahuii & 1 & 1 & 3 & 3 & 1 \\
\hline Browningia candelaris & 1 & 1 & 2 & 2 & 2 \\
\hline Ambrosia artemisioides & 3 & 2 & 3 & 3 & 2 \\
\hline Neoraimondia arequipensis & 1 & + & + & . & 1 \\
\hline Haageocereus platinospinus & 1 & 1 & . & + & + \\
\hline Euphorbia apurimacensis & . & . & . & + & . \\
\hline \multicolumn{6}{|c|}{ Características de orden y clase } \\
\hline Opuntia sphaerica & 1 & 1 & 1 & 1 & 1 \\
\hline \multicolumn{6}{|l|}{ Compañeras } \\
\hline Trixis cacalioides & + & . & + & . & + \\
\hline Ephedra americana & 1 & . & . & + & + \\
\hline Tecoma tanaceiiflora & + & . & . & + & . \\
\hline Balbisia meyeniana & . & . & $\dot{+}$ & 1 & . \\
\hline Atriplex imbricata & + & . & . & . & . \\
\hline Eragrostis weberbaueri & . & 1 & . & . & . \\
\hline Aristida adcensionis & . & 1 & . & . & . \\
\hline Spergularia fasciculata & . & . & + & . & . \\
\hline Krameria lappacea & . & . & 1 & . & . \\
\hline Stipa depauperata & . & . & . & . & 3 \\
\hline Lepidium chichicara & . & . & . & . & + \\
\hline
\end{tabular}

Localidades: 1-5- Arequipa: valle del Colca, proximidades de Huacán [1- 18K 0799034, 8212757; 2- 18K 0799581, 8215436; 3- 18K 0799235, 8215971; 4- 18K 0802072, 8213859; 5- 18K 0799202, 8216782].

se distingue rápidamente por el folíolo terminal alargado y frecuentemente bilobado.

Reunimos a todas las asociaciones caracterizadas por las subespecies de Tecoma fulva en la alianza Tecomion fulvae Galán de Mera \& Cáceres in Galán de Mera 1999, y a ella sinonimizamos la alianza Tecomion arequipensis Galán de Mera \& Cáceres in Galán de Mera, Rosa \& Cáceres 2002, ya que presenta las mismas características y significado ecológico, dentro del orden Acacio macracanthae-Prosopidetalia pallidae Galán de Mera 1999 y la clase Acacio macracanthaeProsopidetea pallidae Galán de Mera 1999.

\footnotetext{
7. Las comunidades con Cactáceas columnares
}

\section{(Clase Opuntietea sphaericae)}

Weberbauerocereo rahuii-Browningietum candelaris Galán de Mera, Linares, Campos \& Vicente Orellana ass. nova [Tabla 11, holotypus ass. inv. 5]

Asociación termotropical árida, entre 2000 y $2150 \mathrm{~m}$, de las laderas occidentales andinas muy pedregosas de origen granítico, cuyas características son Browningia candelaris (Meyen) Britton \& Rose, Neoraimondia arequipensis y Weberbauerocereus rahuii; sobre todo destacamos a $N$. arequipensis que es un bioindicador termotropical.

En el departamento de Arequipa esta asociación forma el paisaje de las zonas de 
menor altitud de los Andes en los valles de Siguas, Colca y Cotahuasi. En los valles de Yura y Chili es sustituida por Weberbauerocereo weberbaueri-Browningietum candelaris Galán de Mera \& Vicente Orellana 1996, que se extiende hasta el departamento de Tacna.

\section{B. Piso mesotropical}

\section{Weberbauerocereo rahuii-Corryocactetum brevistyli Galán de Mera, Linares, Campos \& Vicente Orellana ass. nova \\ [Tabla 12, holotypus ass. inv. 1]}

Asociación mesotropical árido-semiárida que se asienta sobre rocas graníticas y volcánicas que forman las fuertes pendientes aluviales de los cañones del Colca y Cotahuasi, entre los 2300 y $2650 \mathrm{~m}$. A diferencia de la asociación anterior, está ausente Neoraimondia arequipensis, pero están presentes Armatocereus riomajensis, Corryocactus aureus, C. brevistylus (K. Schum. ex Vaupel) Britton \& Rose y Euphorbia apurimacensis Croizat. En los territorios interandinos semiáridos del cañón del Cotahuasi se enriquece con Carica augusti, Croton ruizianus Müll. Arg. y Opuntia subulata (Muehlenpf.) Engelm., por lo que damos a conocer la nueva subasociación crotonetosum ruiziani Galán de Mera, Linares, Campos \& Vicente Orellana subass. nova (holotypus subass. inv. 6).

Esta asociación es sustituida en los valles de Yura, Chili, Uchumayo y área de Yarabamba por Weberbauerocereo weberbaueriCorryocactetum brevistyli Galán de Mera \& Gómez Carrión 2001.

\section{Weberbauerocereo torataensis-} Corryocactetum brevistyli Galán de Mera, Linares, Campos \& Vicente Orellana ass. nova

[Tabla 12, holotypus ass. inv. 8]

La asociación de Weberbauerocereus weberbaueri (K. Schum. ex Vaupel) Backeb. y Corryocactus brevistylus es sustituida por ésta de la laderas occidentales mesotropicales andinas del entorno del río Torata (Moquegua)(2100-2600 m). Presenta una composición florística muy particular, con los endemismos Weberbauerocereus torataensis F. Ritter y Malesherbia ardens J.F. Macbr., y la especie anfiandina Bougainvillea spinosa (Cav.) Heimerl, presente también en las floras de Argentina, Bolivia y Paraguay (Solomon, 2009).

Esta comunidad es sustituida por Corryocacto aurei-Browningietum candelaris Galán de Mera \& Vicente Orellana 1996 en los valles del departamento de Tacna, que se extiende entre 2000 y 3000 m hasta las cercanías de Mamiña (Tarapacá, Chile)(Luebert, 2006).

En el piso supratropical inferior (3000$3500 \mathrm{~m}$ ), donde ya empiezan a penetrar elementos de la puna, las asociaciones con Weberbauerocereus Backeb. encuentran su límite superior, apareciendo especies de Oreocereus (A.Berger) Riccob. (Galán de Mera \& Vicente Orellana, 1996; Luebert \& Gajardo, 2005); así en el departamento de Arequipa, entre el cañón del Colca y Arequipa, reconocemos una comunidad bastante alterada de Oreocereus hendriksenianus y Corryocactus brevistylus, y en Tacna ya describimos Oreocereo tacnaensisCorryocactetum brevistyli Galán de Mera \& Vicente Orellana 1996, que es sustituida en Tarapacá (Chile) por Oreocereo leucotrichiAmbrosietum artemisioidis Luebert \& Gajardo 2005.

Todas estas asociaciones con predominio de Cactáceas quedan reunidas en la alianza oruro-arequipeña Corryocaction brevistyli Galán de Mera \& Vicente Orellana 1996 (Oreocereo leucotrichi-Neoraimondietalia arequipensis Galán de Mera \& Vicente Orellana 1996, Opuntietea sphaericae Galán de Mera \& Vicente Orellana 1996).

Armatocereo riomajensis-Euphorbietum 
Tabla 12

1-5: Werberbauerocereo rahuii-Corryocactetum brevistyli Galán, Linares, Campos \& Vicente ass. nova 6-7: crotonetosum ruiziani Galán, Linares, Campos \& Vicente subass. nova

8-9: Weberbauerocereo torataensis-Corryocactetum brevistyli Galán, Linares, Campos \& Vicente ass. nova (Opuntietea sphaericae, Oreocereo-Neoraimondietalia, Corryocaction brevistyli)

\begin{tabular}{lccccccccc}
\hline Inventario $\mathrm{n}^{\mathrm{o}}$ & 1 & 2 & 3 & 4 & 5 & 6 & 7 & 8 & 9 \\
Área $\left(\mathrm{m}^{2}\right)$ & 100 & 100 & 100 & 100 & 100 & 100 & 100 & 100 & 100 \\
Altitud $(\mathrm{m})$ & 2326 & 2379 & 2380 & 2387 & 2501 & 2657 & 2650 & 2227 & 2359 \\
Pendiente $(\%)$ & 40 & 30 & 10 & - & - & 20 & 20 & 20 & 30
\end{tabular}

Características de asociaciones y alianza

Weberbauerocereus rahuii

Euphorbia apurimacensis

$\begin{array}{llllll}3 & 3 & 3 & 1 & 1 & +\end{array}$

Weberbauerocereus torataensis

Bougainvillea spinosa

Malesherbia ardens

Corryocactus brevistylus

Armatocereus riomajensis

Ambrosia artemisioides

Browningia candelaris

Corryocactus aureus

Haageocereus platinospinus

Oreocereus hempelianus

Diferenciales de subasociación

Croton ruizianus

Opuntia subulata

Carica augusti

Características de orden y clase

Opuntia sphaerica

Compañeras

Stipa depauperata

Ephedra americana

Tagetes multiflora

Puya ferruginea

Tarasa operculata

Opuntia tunicata

Balbisia meyeniana

Krameria lappacea

Encelia canescens

Opuntia ficus-indica

Trixis cacalioides

Proustia berberidifolia

Notholaena nivea

Zinnia peruviana

Verbenaceae

Lycopersicon peruvianum

Localidades: 1-5- Arequipa: valle del Colca, proximidades de Huacán [1- 18K 0800191, 8219321; 2- 18K 0800957, 8219556; 3- 18K 0800980, 8219903; 4- 18K 0801254, 8219873; 5- 18K 0801468, 8220717]; 6 y 7- Arequipa: valle del Cotahuasi, proximidades de Cotahuasi [6- 18L 0727045, 8318258; 7- 18L 0728281, 8319279]; 8- Moquegua: bajo Torata [19K 0304119, 8110463]; 9- Moquegua: de Torata a Omate [19K 0304811, 8111449]. 


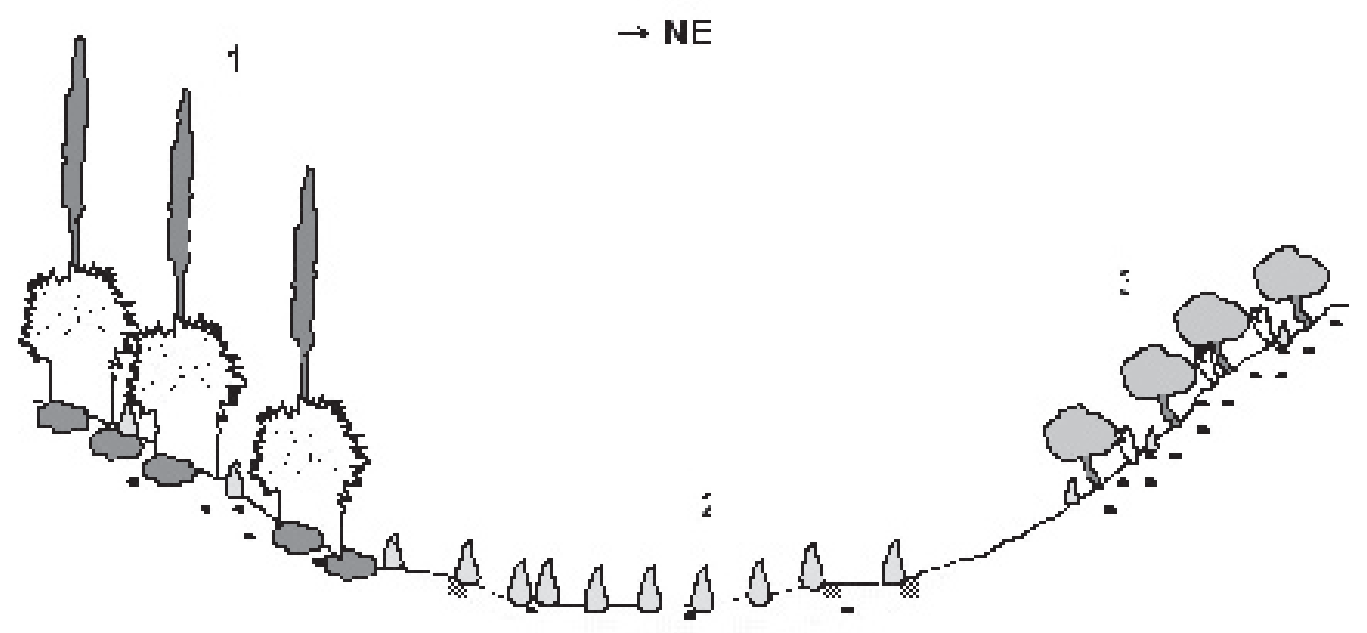

Figura 4. Esquema de la vegetación en el Abra de Querque (Huambo, departamento de Arequipa). 1Comunidades orotropicales subhúmedas de Puya raimondii o "titanca" (Baccharido tricuneatae-Puyetum raimondii), 2- Pastizales con matorrales "pajonal-tolares" orotropicales seco-subhúmedos (Diplostephio tovari-Festucetum orthophyllae), 3- Bosques o "queñuales" orotropicales semiárido-secos (Chuquirago rotundifoliae-Polylepidetum rugulosae). Vegetation scheme of the Querque pass (Huambo, Arequipa department). 1- Orotropical subhumid communities of Puya raimondii or "titanca" (Baccharido tricuneataePuyetum raimondii), 2- Orotropical dry-subhumid grasslands with grass-shrublands or "pajonal-tolares" (Diplostephio tovari-Festucetum orthophyllae), 3- Orotropical semiarid-dry forests or "queñuales" (Chuquirago rotundifoliae-Polylepidetum rugulosae).

apurimacensis Galán de Mera, Linares, Campos \& Vicente Orellana ass. nova [Tabla 13, holotypus ass. inv. 3]

Vegetación mesotropical semiárida (2600$3000 \mathrm{~m}$ ) dominada por el endemismo peruano Euphorbia apurimacensis, que junto con Armatocereus riomajensis y Corryocactus puquiensis, características de la asociación, forman una comunidad muy densa en las pendientes pedregosas graníticas del cañón del Colca. En el piso supratropical es sustituida por Grindelio bergii-Corryocactetum puquiensis Galán de Mera \& Gómez Carrión 2001 nom. corr. hoc loco [Grindelio bolivianaeCorryocactetum puquiensis Galán de Mera \& Gómez Carrión in Acta Bot. Malacitana 26: 245 (2001)], mucho más rica en matorrales; por debajo de los $2600 \mathrm{~m}$ deja paso a la asociación Weberbauerocereo rahuii-Corryocactetum brevistyli, bajo ombroclima árido.

\section{Piso supratropical}

8. Las comunidades de roquedos

(Clase Deuterocohnio longipetalaePuyetea ferrugineae)

\section{Polyachyro sphaerocephali-Puyetum densiflorae Galán de Mera, Linares, Campos \& Vicente Orellana ass. nova}

[Tabla 14, holotypus ass. inv. 3]

Vegetación supratropical $(\sim 3700 \mathrm{~m})$ de los roquedos y grandes bloques volcánicosedimentarios que forman las paredes del cañón del Colca. Se trata de una comunidad donde Puya densiflora Harms, y a veces P. ferruginea (Ruiz \& Pav.) L.B. Sm., se hacen dominantes llegando a alcanzar 1,5 m de altura, y se acompaña de otras plantas fisurícolas de menor talla y amplia distribución, como Cheilanthes pruinata Kaulf., Polyachyrus sphaerocephalus 
Tabla 13

Armatocereo riomajensis-Euphorbietum apurimacensis Galán, Linares, Campos \& Vicente ass. nova (Opuntietea sphaericae, Oreocereo-Neoraimondietalia, Corryocaction brevistyli)

\begin{tabular}{lccccccc}
\hline Inventario $\mathrm{n}^{\mathrm{o}}$ & 1 & 2 & 3 & 4 & 5 & 6 & 7 \\
Área $\left(\mathrm{m}^{2}\right)$ & 100 & 100 & 100 & 100 & 100 & 150 & 100 \\
Altitud $(\mathrm{m})$ & 2699 & 2700 & 2709 & 2714 & 2716 & 2766 & 2770 \\
Pendiente (\%) & 40 & 50 & 35 & 40 & 50 & 10 & 32
\end{tabular}

Características de asociación y alianza

Euphorbia apurimacensis

Armatocereus riomajensis

Ambrosia artemisioides

Corryocactus puquiensis

Corryocactus aureus

Junellia arequipensis

Gochnatia arequipensis

Características de orden y clase

Opuntia tunicata

Opuntia sphaerica

\section{Compañeras}

Tarasa operculata

Cheilanthes pruinata

Dalea cylindrica

Encelia canescens

Bomarea edulis

Stipa ichu

Cheilanthes sinuata

Ephedra americana

Aristida adcensionis

Opuntia subulata

Alonsoa meridionalis

Senna birostris

Sarcostemma solanoides

Bomarea dulcis

Villadia reniformis

Senecio subcandidus

Otras plantas: Pellaea ternifolia 1, Tillandsia usneoides 2 en 1; Croton ruizianus 1 en 2; Monnina ramosa 1, Grindelia bergii 1, Bouteloua simplex 1 en 5; Mentzelia fendleriana + , Krameria lappacea 1, Eragrostis peruviana + en 6; Lepthochloa uniflora 1, Hoffmannseggia prostrata + , Lycianthes lycioides,+ Baccharis uniflora + en 7.

Localidades: 1-7- Arequipa, cañón del Colca, entre Cabanaconde y Soro [1- 18L 0820001, 8274331; 2- 18L 0820029, 8275863; 3- 18L 0820051, 8274304; 4- 18L 0820146, 8274278; 5- 18L 0820073, 8274200; 6- 18L 0820015, 8274140]; 7- 18L 0819885, 8274115]. 
Tabla 14

Polyachyro sphaerocephali-Puyetum densiflorae Galán, Linares, Campos \& Vicente ass. nova (Deuterocohnio-Puyetea, Polypodio-Puyetalia, Peperomio-Puyion)

\begin{tabular}{|c|c|c|c|c|c|c|}
\hline Inventario $\mathrm{n}^{\mathrm{o}}$ & 1 & 2 & 3 & 4 & 5 & 6 \\
\hline Área $\left(m^{2}\right)$ & 100 & 50 & 100 & 100 & 100 & 25 \\
\hline Altitud (m) & 3764 & 3767 & 3747 & 3744 & 3744 & 3744 \\
\hline Pendiente $(\%)$ & 90 & 80 & 70 & 70 & 70 & 60 \\
\hline \multicolumn{7}{|c|}{ Características de asociación y alianza } \\
\hline Puya densiflora & 2 & 3 & 3 & 3 & 3 & 2 \\
\hline Polyachyrus sphaerocephalus & 1 & . & + & . & . & . \\
\hline \multicolumn{7}{|l|}{ Características de orden y clase } \\
\hline Cheilanthes pruinata & + & . & 1 & + & . & . \\
\hline Villadia reniformis & . & . & . & + & . & . \\
\hline \multicolumn{7}{|l|}{ Compañeras } \\
\hline Grindelia bergii & 2 & 2 & 2 & 2 & 1 & 2 \\
\hline Opuntia subulata & 1 & . & 1 & 2 & 1 & 1 \\
\hline Mutisia acuminata & + & + & + & + & . & + \\
\hline Ophryosporus peruvianus & & + & 1 & 1 & 1 & 1 \\
\hline Proustia berberidifolia & 1 & . & 1 & 1 & + & . \\
\hline Calamagrostis intermedia & 1 & . & . & . & 1 & . \\
\hline Chersodoma jodoppapa & . & 1 & + & . & . & . \\
\hline Cantua buxifolia & . & . & 1 & . & + & . \\
\hline Corryocactus puquiensis & . & . & . & + & + & . \\
\hline Conyza sp. & + & . & . & . & . & . \\
\hline Colletia spinosissima & . & . & 1 & . & . & . \\
\hline Sisymbrium $s p$. & . & . & + & . & . & . \\
\hline Diplostephium tacorense & . & . & . & + & . & . \\
\hline Opuntia soehrensii & . & . & . & + & . & . \\
\hline Lupinus mutabilis & . & . & . & 1 & . & . \\
\hline Spergularia fasciculata & . & . & . & + & . & . \\
\hline
\end{tabular}

Localidades: 1-6- Arequipa, cañón del Colca, proximidades de la Cruz del Cóndor [1- 19L 0188645, 8272051; 2- 19L 0188692, 8272049; 3- 19L 0188857, 8272075; 4- 19L 0188978, 8272091; 5- 19L 0189042, 8272062; 6- 19L 0189270, 8272110].

D. Don y Villadia reniformis H. Jacobsen.

Indudablemente incluimos esta asociación en la alianza Peperomio galioidis-Puyion ferrugineae Galán de Mera \& Rosa in Galán de Mera, Rosa \& Cáceres 2002 y en el orden andino Polypodio pycnocarpi-Puyetalia ferrugineae Galán de Mera \& Rosa in Galán de Mera, Rosa \& Cáceres 2002

A esta alianza también pertenecen las comunidades ancashino-paceñas de Senecio velardei Cabrera y Tillandsia oroyensis $\mathrm{Mez}$ (Galán de Mera et al., 2004), y de P.ferruginea y Trichocereus peruvianus Britton \& Rose
(Gutte, 1986).

El orden Polypodio-Puyetalia es vicariante de Deuterocohnio longipetalaePuyetalia ferrugineae Navarro 2002 descrito con comunidades bolivianas (Navarro \& Maldonado, 2005), que podría tratarse de una versión más oriental de este tipo de comunidades; al menos los inventarios levantados por Seibert \& Menhofer (1991) en la cordillera de Apolobamba (Bolivia) presentan las plantas características de Polypodio-Puyetalia. Ambos órdenes quedan reunidos en la clase andina neotropical Deuterocohnio longipetalae- 
Tabla 15

\begin{tabular}{|c|c|c|c|}
\hline \multicolumn{4}{|c|}{$\begin{array}{c}\text { Diplostephio tovari-Festucetum orthophyllae } \\
\text { Galán, Linares, Campos \& Vicente ass. nova } \\
\text { (Calamagrostietea vicunarum, Parastrephietalia } \\
\text { lepidophyllae, Azorello-Festucion) }\end{array}$} \\
\hline Inventario $\mathrm{n}^{\mathrm{o}}$ & 1 & 2 & 3 \\
\hline Área $\left(\mathrm{m}^{2}\right)$ & 200 & 100 & 100 \\
\hline Altitud (m) & 4003 & 4254 & 4254 \\
\hline Pendiente $(\%)$ & 50 & 30 & 30 \\
\hline \multicolumn{4}{|c|}{ Características de asociación y alianza } \\
\hline Festuca orthophylla & 4 & 4 & 4 \\
\hline Diplostephium tovari & $\cdot$ & 2 & 1 \\
\hline Parastrephia quadrangulare & 1 & . & . \\
\hline Parastrephia lucida & & . & + \\
\hline \multicolumn{4}{|c|}{ Características de orden y clase } \\
\hline Baccharis tricuneata & 1 & 1 & 1 \\
\hline Nassella pubiflora & 2 & 1 & 1 \\
\hline Chersodoma jodoppapa & 1 & 1 & 1 \\
\hline Parastrephia lepidophylla & . & 1 & 1 \\
\hline Senecio nutans & . & 1 & 1 \\
\hline Astragalus garbancillo & . & + & . \\
\hline Calamagrostis curvula & . & . & 1 \\
\hline \multicolumn{4}{|l|}{ Compañeras } \\
\hline Polylepis rugulosa & + & . & . \\
\hline Belloa piptholepis & + & . & . \\
\hline Chuquiraga rotundifolia & + & . & . \\
\hline Avena sp. & . & 1 & . \\
\hline
\end{tabular}

Localidades: 1-3- Arequipa: Huambo, Abra de Querque [1-18L 0807932, 8244542; 2- 18L 0845261, 8238019; 3- 18L 0812578, 8236099].

Puyetea ferrugineae Rivas-Martínez \& Navarro in Navarro \& Maldonado 2002.

\section{Piso orotropical}

9. Los pajonal-tolares interandinos (fig. 4) (Clase Calamagrostietea vicunarum)

\section{Diplostephio tovari-Festucetum ortophyllae} Galán de Mera, Linares, Campos \& Vicente Orellana ass. nova

[Tabla 15, holotypus ass. inv. 2]

Pajonal de Festuca orthophylla Pilg. y caméfitos dispersos entre los que destaca el endemismo oruro-arequipeño interandino
Diplostephium tovari, que es la especie característica de la asociación.

Se trata de una asociación del piso bioclimático orotropical seco-subhúmedo ( $\sim 4000 \mathrm{~m})$ que se asienta sobre sustratos volcánicos sedimentarios ricos en cenizas compactadas y pequeños cantos andesíticos. Sustituye al Parastrephio lucidae-Festucetum orthophyllae Galán de Mera, Cáceres \& González 2003 en los valles interandinos de los departamentos de Arequipa y Ayacucho.

La presencia en los inventarios de Festuca orthophylla, Nassella pubiflora (Trin. \& Rupr.) E. Desv., Parastrephia lucida (Meyen) Cabrera y P. quadrangularis (Meyen) Cabrera, permiten su inclusión en la alianza oruro-arequipeña Azorello-Festucion orthophyllae Galán de Mera, Cáceres \& González 2003 (Galán de Mera et al., 2003a; Luebert \& Gajardo, 2005).

10. Las comunidades de "titanca" de la puna seca (fig. 4)

(Clase Calamagrostietea vicunarum)

Baccharido tricuneatae-Puyetum raimondii Galán de Mera, Linares, Campos \& Vicente Orellana ass. nova

[Tabla 16, holotypus ass. inv. 1]

Hasta ahora no conocíamos a Puya raimondii Harms ("titanca") ni en el departamento de Arequipa ni en la puna seca de la provincia Oruro-Arequipeña, siendo un elemento de la provincia Paramuno-Peruana (páramo del departamento de La Libertad) y de la provincia Ancashino-Paceña (puna húmeda de los departamentos de Ancash, Huancavelica y Puno en el Perú, y de la Paz y Cochabamba en Bolivia)(Brako \& Zarucchi, 1993; HornungLeoni \& Sosa, 2008). Gutte (1985) describió la asociación Orthosantho occissapongis-Puyetum raimondii del piso orotropical de la puna húmeda del centro del Perú, cuya composición florística es muy diferente a ésta del S del Perú 
Tabla 16

Baccharido tricuneatae-Puyetum raimondii Galán, Linares, Campos \& Vicente ass. nova (Calamagrostietea vicunarum, Parastrephietalia lepidophyllae, Azorello-Festucion)

\begin{tabular}{lccccccc}
\hline Inventario $\mathrm{n}^{\mathrm{o}}$ & 1 & 2 & 3 & 4 & 5 & 6 & 7 \\
Área $\left(\mathrm{m}^{2}\right)$ & 200 & 200 & 200 & 100 & 100 & 100 & 100 \\
Altitud $(\mathrm{m})$ & 4365 & 4342 & 4337 & 4086 & 4098 & 4134 & 4036 \\
Pendiente $(\%)$ & 30 & 40 & 40 & 50 & 50 & 50 & 50
\end{tabular}

Características de asociación y alianza

Puya raimondii

Baccharis tricuneata

Diplostephium tovari

Festuca orthophylla

Parastrephia quadrangularis

$\begin{array}{lllllll}3 & 1 & 2 & 2 & 1 & 1 & 1 \\ 1 & 3 & 1 & 4 & 1 & 1 & 1 \\ 1 & 1 & 1 & . & . & . & 1 \\ 2 & 1 & 2 & . & . & . & . \\ 1 & . & . & . & . & . & .\end{array}$

Características de orden y clase

Stipa ichu

Nassella pubiflora

Tetraglochin cristatum

Baccharis buxifolia

Chersodoma jodoppapa

Nassella brachyphylla

Lovibia pampana

Diplostephium tacorense

Bartsia camporum

Opuntia soehrensii

Senecio phylloleptus

Opuntia ignescens

Calamagrostis curvula

Calceolaria xerophila

Calceolaria inamoena

Calamagrostis vicunarum

Opuntia floccosa

Geranium sessiliflorum

\section{Compañeras}

Ribes brachybotrys

Mutisia orbignyana

Muhlenbergia peruviana

Chuquiraga rotundifolia

Mutisia hastata

\begin{tabular}{|c|c|c|c|c|c|}
\hline 3 & 2 & 3 & 2 & 2 & 3 \\
\hline 4 & 4 & 4 & & 1 & 1 \\
\hline 1 & 1 & . & 3 & 2 & 2 \\
\hline & & & 1 & 1 & 1 \\
\hline 1 & 1 & 1 & . & . & . \\
\hline+ & . & . & 1 & 1 & . \\
\hline . & . & . & 2 & + & . \\
\hline+ & + & . & . & . & . \\
\hline+ & . & + & . & . & . \\
\hline+ & . & + & . & . & . \\
\hline+ & . & + & . & . & . \\
\hline . & 1 & + & . & : & . \\
\hline . & . & . & . & 1 & . \\
\hline . & . & . & . & . & 1 \\
\hline . & . & . & . & . & 1 \\
\hline . & . & . & . & . & . \\
\hline . & . & . & . & . & . \\
\hline . & . & . & . & . & . \\
\hline 2 & . & 2 & . & + & . \\
\hline+ & 2 & + & . & . & . \\
\hline . & . & . & 1 & 1 & . \\
\hline . & . & . & 1 & 1 & . \\
\hline . & . & . & . & + & 1 \\
\hline
\end{tabular}

Otras plantas: Solanum sp. 1 en 2; Bomarea uniflora + , Cheilanthes pruinata + en 5; Buddleja coriacea 2, Poa candamoana 1, Escallonia myrtilloides 1 en 6; Puya ferruginea 2, Belloa piptolepis + , Plantago sericea subsp. sericans + en 7.

Localidades: 1-3- Arequipa: Huambo, Abra de Querque [1- 18L 0801962, 8208274; 2- 18L 0802321, 8208098; 3- 18L 0802617, 8238005]; 4-7- Arequipa, valle del Cotahuasi, Lauripampa [4- 18L 0746650, 8347656; 5- 18L 0746630, 8347752; 6- 18L 0746624, 8348317; 7- 18L 0746649, 8348394]. 
(Calamagrostis antoniana (Griseb.) Hack., Liabum bullatum (A. Gray ex Wedd.) Hieron., Lupinus microphyllus Nutt. ex Torr. \& A. Gray, Luzula racemosa Desv., Stipa hans-meyeri Pilg., Werneria nubigena Kunth).

Baccharido-Puyetum es una asociación orotropical subhúmeda que tiene preferencias por pendientes muy pedregosas con grandes bloques de andesitas que se estabilizan con el desarrollo de la "titanca", matorrales (Baccharis tricuneata (L. f.) Pers., Chersodoma jodopappa (Sch. Bip.) Cabrera, Diplostephium tovari) y gramíneas vivaces (Festuca orthophylla, Nassella pubiflora (Trin. \& Rupr.) E. Desv., Stipa ichu (Ruiz \& Pav.) Kunth).

La orientación NE de todas las localidades sugiere la presencia relictual de $P$. raimondii que tiende a ocupar las posiciones más húmedas y similares a las propias de la puna húmeda, y a las de $P$. fastuosa Mez en la provincia Paramuno-Peruana (Sánchez Vega et al., 2005). En las vaguadas y valles situados a más de $4000 \mathrm{~m}$, entra en contacto (inventarios 1-3) con Diplostephio tovari-Festucetum orthophyllae, y su orientación se opone a la de los bosquetes de Chuquirago rotundifoliae-Polylepidetum rugulosae (Galán de Mera, Cáceres \& González) Luebert \& Gajardo 2005 (fig. 4).

La combinación de $P$. raimondii con Diplostephium tovari, Festuca orthophylla y Parastrephia quadrangularis, permite incluir esta asociación en la alianza Azorello compactaeFestucion orthophyllae Galán de Mera, Cáceres \& González 2003 (Parastrephietalia lepidophyllae Navarro 1993, Calamagrostietea vicunarum Rivas-Martínez \& Tovar 1982).

\section{CONCLUSIONES}

Como conclusión damos a conocer el esquema sintaxonómico que reconocemos hasta el momento en el S del Perú, ordenado (Galán de Mera et al., 2004) por formaciones vegetales, con la diagnosis sintetizada de las asociaciones y subasociaciones.

\author{
I. Arbustedas y bosques climatófilos \\ de la costa
}

CARICO CANDICANTIS-CAESALPINIETEA SPINOSAE Galán de Mera, Linares, Campos \& Vicente Orellana cl. nova

+Citharexylo flexuosi-Crotonetalia alnifolii Galán de Mera, Linares, Campos \& Vicente Orellana ordo novo

* Grindelion glutinosae Galán de Mera, Linares, Campos \& Vicente Orellana all. nova

1. Caesalpinio spinosae-Myrcianthetum ferreyrae Galán de Mera, Linares, Campos \& Vicente Orellana ass. nova [Bosques termotropicales secos]

2. Echinopsio chalaensis-Randietum armatae Galán de Mera, Linares, Campos \& Vicente Orellana ass. nova [Espinales termotropicales semiáridos]

\section{La vegetación herbácea de las lomas costaneras}

PALAUO DISSECTAE-NOLANETEA GAYANAE Galán de Mera 2005

+ Commelinetalia fasciculatae Galán de Mera \& Rosa in Galán de Mera, Rosa \& Cáceres 2002

* Loasion urentis Galán de Mera \& Rosa in Galán de Mera, Rosa \& Cáceres 2002

3. Hoffmannseggio mirandae-Palauetum weberbaueri Galán de Mera, Linares, Campos \& Vicente Orellana ass. nova [Asociación de arenas estabilizadas]

4. Nolano spathulatae-Palauetum dissectae Galán de Mera, Linares, Campos \& Vicente Orellana ass. nova [Vegetación de suelos arenosos poco estabilizados]

TILLANDSIETEA LANDBECKII Galán de Mera \& Gómez Carrión 2003

+ Tillandsietalia landbeckii Galán de Mera \& Gómez Carrión 2003

* Tillandsion latifoliae Galán de Mera \& Gómez Carrión 2003

5. Tillandsietum purpureo-latifoliae Müller 1985 [Aerófitos sobre dunas estabilizadas]

* Tillandsion werdermannii Galán de Mera \& Gómez Carrión 2003

6. Cistantho tovari-Tillandsietum werdermannii Galán de Mera 1996 [Aerófitos de dunas estabilizadas de las planicies de Moquegua y Tacna] 


\section{La vegetación de los saladares de la costa}

BATIDO-SARCOCORNIETEA AMBIGUAE Borhidi 1991, nom. mut. propos. [Batido-Salicornietea ambiguae]

+ Sarcocornietalia neei Galán de Mera, Linares, Campos \& Vicente Orellana ordo novo

* Sarcocornio neei-Distichlion spicatae Galán de Mera, Linares, Campos \& Vicente Orellana all. nova

7. Cresso truxillensis-Distichlietum spicatae Galán de Mera, Linares, Campos \& Vicente Orellana ass. nova [Vegetación de suelos arenosos salinos]

8. Cypero laevigati-Distichlietum spicatae Galán de Mera, Linares, Campos \& Vicente Orellana ass. nova [Asociación de suelos salinos húmedos que no llegan a encharcarse]

9. Sarcocornietum neei Müller \& Gutte 1983, nom. mut. propos. [Salicornietum peruvianae; asociación de saladares de suelos profundos e inundación intermitente]

10. Sporobolo virginici-Distichlietum spicatae Galán de Mera, Linares, Campos \& Vicente Orellana ass. nova [Gramadal costero que limita con el desierto litoral]

\section{La vegetación helofítica de la costa y los Andes}

\section{PLANTAGINETEA AUSTRALIS Gutte 1986}

11. Comunidad de Polypogon interruptus y Eleocharis geniculata [Juncales y herbazales de pequeñas depresiones encharcadas de los pisos meso- y supratropical]

12. Comunidad de Rorippa nasturtium-aquaticum y Veronica anagallis-aquatica [Comunidades invasoras de origen holártico de los pisos termosupratropical]

XYRIDO CAROLINIANAE-TYPHETEA DOMINGENSIS O. Bolòs, Cervi \& Hatschbach 1991

+ Equiseto gigantei-Typhetalia domingensis $\mathrm{O}$. Bolòs, Cervi \& Hatschbach 1991

* Equiseto gigantei-Typhion domingensis O. Bolòs, Cervi \& Hatschbach 1991

13. Bacopo monnieri-Typhetum domingensis Galán de Mera 1995 [Grandes helófitos de la costa peruana y chilena neotropical]
* Cortaderion jubatae Galán de Mera, Cáceres \& González 2003

14. Cortaderietum jubatae Galán de Mera, Cáceres \& González 2003 [Helófitos de cauces andinos mesoy supratropicales]

+ Schoenoplectetalia olneyi-americani Galán de Mera, Linares, Campos \& Vicente Orellana ordo novo

* Ludwigio octovalvis-Paspalion vaginati Galán de Mera, Linares, Campos \& Vicente Orellana all. nova

15. Lippio nodiflorae-Paspaletum vaginati Galán de Mera, Linares, Campos \& Vicente Orellana ass. nova [Gramadales dulces de la costa pacífica inundados por aguas salobres]

paspaletosum vaginati

schoenoplectetosum olneyii Galán de Mera, Linares, Campos \& Vicente Orellana subass. nova [Suelos frecuentemente inundados]

16. Schoenoplectetum olneyi-americani Galán de Mera, Linares, Campos \& Vicente Orellana ass. nova [Juncales de la costa pacífica]

\section{Comunidades de freatófitos y el monte ribereño de la costa}

ACACIO MACRACANTHAE-PROSOPIDETEA PALLIDAE Galán de Mera 1999

+ Acacio macracanthae-Prosopidetalia pallidae Galán de Mera 1999

* Tecomion fulvae Galán de Mera \& Cáceres in Galán de Mera 1999

17. Acacio macracanthae-Tecometum guarumis Galán de Mera, Linares, Campos \& Vicente Orellana ass. nova [Asociación termo-mesotropical de freatófitos de las quebradas de Ica]

18. Schino mollis-Tecometum arequipensis Galán de Mera, Linares, Campos \& Vicente Orellana ass. nova [Freatófitos termo-mesotropicales del SE de Arequipa y NO de Moquegua]

19. Schino mollis-Tecometum tanaceiiflorae Galán de Mera, Linares, Campos \& Vicente Orellana ass. nova [Freatófitos termo-mesotropicales de las quebradas tributarias del río Colca (Arequipa)]

20. Tecometum fulvae Galán de Mera 1996 [Freatófitos termo-mesotropicales del extremo $\mathrm{S}$ del Perú y $\mathrm{N}$ de Chile]

TESSARIO INTEGRIFOLIAE-BACCHARIDETEA SALICIFOLIAE Rivas-Martínez \& Navarro in 
Navarro \& Maldonado 2002

+ Plucheo absinthioidis-Baccharidetalia salicifoliae Rivas-Martínez \& Navarro in Navarro \& Maldonado 2002

* Plucheion absinthioidis Galán de Mera, Linares, Campos \& Vicente Orellana all. nova

21. Plucheetum absinthioidis Galán de Mera, Linares, Campos \& Vicente Orellana ass. nova [Arbustedas costeras de suelos salinos]

22. Comunidad de Geoffroea decorticans [Freatófitos halófilos sobre costras poligonales]

\section{Las comunidades con cactáceas columnares}

OPUNTIETEA SPHAERICAE Galán de Mera \& Vicente Orellana 1996

+ Oreocereo leucotrichi-Neoraimondietalia arequipensis Galán de Mera \& Vicente Orellana 1996

* Haageocerion australis Galán de Mera, Cáceres \& González 2002

23. Neoporterio islayensis-Neoraimondietum arequipensis Galán de Mera, Cáceres \& González 2002 [Cactáceas columnares termotropicales áridas costeras]

* Corryocaction brevistyli Galán de Mera \& Vicente Orellana 1996

24. Armatocereo riomajensis-Euphorbietum apurimacensis Galán de Mera, Linares, Campos \& Vicente Orellana ass. nova [Vegetación mesotropical semiárida del cañón del Colca (Arequipa)]

25. Comunidad de Oreocereus hendriksenianus y Corryocactus brevistylus [Vegetación supratropical inferior semiárida-árida del departamento de Arequipa]

26. Corryocacto aurei-Browningietum candelaris Galán de Mera \& Vicente Orellana 1996 [Asociación mesotropical árida de los departamentos de Tacna (Perú) y Tarapacá (Chile)]

27. Grindelio bergii-Corryocactetum puquiensis Galán de Mera \& Gómez Carrión 2001, nom. corr. hoc loco [Grindelio bolivianae-Corryocactetum puquiensis Galán de Mera \& Gómez Carrión in Acta Bot. Malacitana 26: 245 (2001); asociación supratropical inferior semiárida de los valles interandinos del departamento de Arequipa]

28. Oreocereo tacnaensis-Corryocactetum brevistyli Galán de Mera \& Vicente Orellana 1996 [Asociación supratropical inferior semiárida del departamento de Tacna]
29. Weberbauerocereo rahuii-Browningietum candelaris Galán de Mera, Linares, Campos \& Vicente Orellana ass. nova [Asociación termotropical árida de los valles de Siguas, Colca y Cotahuasi (Arequipa)]

30. Weberbauerocereo rahuii-Corryocactetum brevistyli Galán de Mera, Linares, Campos \& Vicente Orellana ass. nova [Asociación mesotropical áridosemiárida de los cañones del Colca y Cotahuasi (Arequipa)]

corryocactetosum brevistyli

crotonetosum ruiziani Galán de Mera, Linares, Campos \& Vicente Orellana subass. nova [Aspecto de la asociación en el cañón del Cotahuasi bajo ombroclima semiárido]

31. Weberbauerocereo torataensis-Corryocactetum brevistyli Galán de Mera, Linares, Campos \& Vicente Orellana ass. nova [Asociación mesotropical árida del valle de Torata (Moquegua)]

32. Weberbauerocereo weberbaueri-Browningietum candelaris Galán de Mera \& Vicente Orellana 1996 [Asociación termotropical árida, desde los alrededores de Arequipa al departamento de Tacna]

33. Weberbauerocereo weberbaueriCorryocactetum brevistyli Galán de Mera \& Gómez Carrión 2001 [Asociación mesotropical árida de los valles de Yura, Chili, Uchumayo y área de Yarabamba (Arequipa)]

\section{Los matorrales ("tolares") y pajonal-tolares}

CALAMAGROSTIETEA VICUNARUM RivasMartínez \& Tovar 1982

+ Parastrephietalia lepidophyllae Navarro 1993

* Fabianion stephanii Galán de Mera, Cáceres \& González 2003

34. Diplostephio tacorensis-Parastrephietum lepidophyllae Galán de Mera, Cáceres \& González 2003 [Matorrales supratropicales semiárido-secos] parastrephietosum lepidophyllae

corryocactetosum brevistyli Galán de Mera, Cáceres \& González 2003 [Subasociación de suelos poco cohesionados]

* Azorello compactae-Festucion orthophyllae Galán de Mera, Cáceres \& González 2003

35. Baccharido tricuneatae-Puyetum raimondii Galán de Mera, Linares, Campos \& Vicente Orellana ass. nova [Comunidades orotropicales subhúmedas 
oruro-arequipeñas con Puya raimondii]

36. Diplostephio tovari-Festucetum orthophyllae Galán de Mera, Linares, Campos \& Vicente Orellana ass. nova [Pajonal-tolares orotropicales secosubhúmedos de valles interandinos]

37. Parastrephio lucidae-Festucetum orthophyllae Galán de Mera, Cáceres \& González 2003 [Pajonaltolares orotropicales seco-subhúmedos extendidos por la provincia Oruro-Arequipeña]

festucetosum orthophyllae azorelletosum compactae Galán de Mera, Cáceres \& González 2003 [Subasociación de pedreras fijas]

VIII. Los bosques de queñua

\section{POLYLEPIDETEA TARAPACANO-BESSERI Rivas-} Martínez \& Navarro in Navarro \& Maldonado 2002

+ Polylepidetalia racemosae Galán de Mera \& Cáceres in Galán de Mera, Rosa \& Cáceres 2002

* Ribesido brachybotrys-Polylepidion rugulosae Galán de Mera \& Cáceres in Galán de Mera, Rosa \& Cáceres 2002, nom.corr. hoc loco [Ribesido brachybotrys-Polylepidetum besseri]

38. Chuquirago rotundifoliae-Polylepidetum rugulosae (Galán de Mera, Cáceres \& González 2003) Luebert \& Gajardo 2005 [Queñuales orotropicales semiárido-secos de la provincia Oruro-Arequipeña occidental]

39. Mutisio lanigerae-Polylepidetum tarapacanae Navarro in Navarro \& Maldonado 2002 [Queñuales oro-criorotropicales secos de la provincia OruroArequipeña]

\section{Arbustedas andinas}

BACCHARIDETEA LATIFOLIAE Lauer, Rafiqpoor \& Theisen 2001

+ Mutisio acuminatae-Baccharidetalia latifoliae Galán de Mera \& Cáceres in Galán de Mera, Rosa \& Cáceres 2002

* Mutisio acuminatae-Ophryosporion peruvianae Galán de Mera \& Cáceres in Galán de Mera, Rosa \& Cáceres 2002

40. Dunalio spinosae-Baccharidetum latifoliae Galán de Mera, Cáceres \& González 2003 [Arbustedas de suelos húmedos meso-supratropicales oruroarequipeñas]

baccharidetosum latifoliae

otholobietosum pubescentis Galán de Mera, Cáceres
\& González 2003 [Suelos eutrofizados] calamagrostietosum intermediae Galán de Mera, Cáceres \& González 2003 [Huertos incendiados y abandonados]

\section{Las comunidades de roquedos}

DEUTEROCOHNIO LONGIPETALAE-PUYETEA

FERRUGINEAE Rivas-Martínez \& Navarro in Navarro \& Maldonado 2002

+ Polypodio pycnocarpi-Puyetalia ferrugineae Galán de Mera \& Rosa in Galán de Mera, Rosa \& Cáceres 2002

* Peperomio galioidis-Puyion ferrugineae Galán de Mera \& Rosa in Galán de Mera, Rosa \& Cáceres 2002

41. Polyachyro sphaerocephali-Puyetum densiflorae Galán de Mera, Linares, Campos \& Vicente Orellana ass. nova [Vegetación supratropical de los roquedos del cañón del Colca]

NOTHOLAENETEA NIVEAE Gutte 1986

+ Salpichroetalia glandulosae Galán de Mera, Cáceres \& González 2003

* Belloo schultzii-Salpichroion glandulosae Galán de Mera, Cáceres \& González 2003

42. Chersodomo diclinae-Valerianetum nivalis Galán de Mera, Cáceres \& González 2003

[Vegetación fisurícola oro- y criorotropical]

\section{Vegetación de suelos poligonales y pedregales}

ANTHOCHLOO LEPIDULAEDIELSIOCHLOETEA FLORIBUNDAE RivasMartínez \& Tovar 1982

+Anthochloo lepidulae-Dielsiochloetalia floribundae Rivas-Martínez \& Tovar 1982

* Nototrichion obcuneatae Galán de Mera, Cáceres \& González 2003

43. Belloo piptolepis-Dissanthelietum calycini Galán de Mera, Cáceres \& González 2003 [Graminales supra-criorotropicales de suelos poligonales]

dissanthelietosum calycini

azorelletosum diapensioidis Galán de Mera, Cáceres \& González 2003 [Subasociación de la zona más septentrional de la puna seca]

44. Nototricho obcuneatae-Xenophylletum poposi Galán de Mera, Cáceres \& González 2003 [Vegetación oro-criorotropical de pedregales móviles] 
xenophylletosum poposi

valerianetosum nivalis Galán de Mera, Cáceres \& González 2003 [Subasociación de cantos fijos y gruesos]

\section{Vegetación de las turberas andinas}

PLANTAGINI RIGIDAE-DISTICHIETEA MUSCOIDIS Rivas-Martínez \& Tovar 1982

+ Plantaginetalia tubulosae Gutte 1985

* Hypsello reniformis-Plantaginion tubulosae Galán de Mera, Cáceres \& González 2003

45. Eleocharito tucumanensis-Plantaginetum tubulosae Seibert 1993 [Bofedales del S del Perú y Bolivia]

* Oxychloion andinae Ruthsatz 1995

46. Wernerio pygmaeae-Puccinellietum oresigenae Galán de Mera, Cáceres \& González 2003 [Turberas de aguas salobres del altiplano peruano]

+ Calamagrostietalia nitidulae Galán de Mera, Cáceres \& González 2003

* Calamagrostion chrysanthae Rivas-Martínez \& Tovar 1982

47. Calamagrostietum nitidulo-chrysanthae Gutte 1980 [Graminales iniciadores de la formación de turberas]

\section{Vegetación acuática andina}

CABOMBO-NYMPHAEETEA Borhidi \& Del Risco ex Borhidi 1996

+ Nymphaeetalia amplae Knapp ex Borhidi 1996

* Potamion illinoensis Borhidi 1996

48. Myriophylletum quitensis Seibert 1993 [Aguas profundas oligotróficas]

\section{myriophylletosum quitensis}

elodeetosum potamogetonis Galán de Mera, Cáceres \& González 2003 [Aguas con aumento de nitrógeno orgánico]

49. Ranunculetum limoselloidis Galán de Mera, Cáceres \& González 2003

[Aguas someras oligotróficas]

50. Stuckenietum punensis Galán de Mera, Cáceres \& González 2003 [Aguas corrientes]

LEMNETEA MINORIS R. Tx. ex O. Bolòs \& Masclans 1955

+ Lemnetalia gibbae Landolt 1999, prov.

* Azollo filiculoidis-Lemnion gibbae Landolt 1999, prov.

51. Lemnetum minuto-gibbae Libermann Cruz, Pedrotti \& Venanzoni 1988 [Acropleustófitos de aguas oligotróficas]

AGRADECIMIENTOS. Gracias a los herbarios AQP, F, HUSA, MO, NY, US, USM y USP que pusieron a nuestra disposición la información necesaria para la realización de este trabajo. En lo económico y logístico tuvimos la ayuda de la Agencia Española de Cooperación Internacional (Programa de Cooperación Cultural y Científica, 2007), de la Asociación Universitaria Iberoamericana de Postgrado de España (2008), de los profesores Francisco Villasante y Carmelo Talavera (Universidad Nacional de San Agustín, Arequipa, Perú) y de la Cátedra de Desarrollo Sostenible y Medio Ambiente de la Universidad San Pablo-CEU-Banco de Santander (2008 y 2009). Algunos de los inventarios fueron levantados con los alumnos de los cursos de Geobotánica y de Conservación de la Flora y de la Fauna de la Licenciatura de Ciencias Ambientales de la Universidad San Pablo-CEU durante el viaje de prácticas realizado al sur del Perú en noviembre de 2008.

\section{BIBLIOGRAFÍA}

ALONSO, M.A. \& M.B. CRESPO-2008-Taxonomic and nomenclatural notes on South American taxa of Sarcocornia (Chenopodiaceae). Ann. Bot. Fenn. 45: 241-254.

BORHIDI, A. -1991-Phytogeography and Vegetation Ecology of Cuba. Akadémici Kiadó, Budapest.

BORHIDI, A. -1996-Phytogeography and Vegetation Ecology of Cuba. Akadémici Kiadó, Budapest.

BORHIDI, A., O. MUÑIZ \& E. DEL RISCO -1979Clasificación fitocenológica de la vegetación de Cuba. Acta Bot. Acad. Sci. Hung. 25: 263-301.

BORHIDI, A., O. MUÑIZ \& E. DEL RISCO -1983Plant communities of Cuba, I. Fresh and salt water, swamp and coastal vegetation. Acta Bot. Hung. 29: 337-376.

BRACK EGG, A. -1999- Diccionario enciclopédico de las plantas útiles del Perú. CBC, Cusco.

BRACK EGG, A. y C. MENDIOLA VARGAS 2004- Ecología del Perú. Bruño, Lima.

BRAKO, L. y J.L. ZARUCCHI -1993- Catálogo de las Angiospermas y Gimnospermas del Perú. Missouri Botanical Garden, St. Louis. 
BRAUN-BLANQUET, J. -1932- Plant Sociology. The study of plant communities. Koeltz Scientific Books, Koenigstein.

BRUNS, F. -1929- Beiträge zur Kenntnis der Vegetation des peruanischen Küstengebietes. Hamburg.

DILLON, M.O., S. LEIVA GONZÁLEZ \& V. QUIPUSCOA SILVESTRE -2007- Five new species of Nolana (Solanaceae-Nolaneae) from Peru and notes on the classification of additional taxa. Arnaldoa 14: 171-190.

ELLENBERG, H. -1959- Über den Wasserhaushalt tropischer Nebeloasen in der Küstenwüste Perus. Ber. Geobot. Forschungsinst. Rübel Zürich 1958: 47-74.

FERREYRA, R. -1953-Comunidades vegetales de algunas lomas costaneras del Perú. Bol. Estac. Exp. Agríc. "La Molina”, Bol. 53: 1-88.

FERREYRA, R. -1960-Algunos aspectos fitogeográficos del Perú. Publ. Inst. Geogr. Univ. San Marcos serie I(B): 41-87.

FERREYRA, R. -1983- Los tipos de vegetación de la costa peruana. Anales Jard. Bot. Madrid 40(1): 241-256.

GALÁNDEMERA,A. -1995-Ensayo sintaxonómico sobre las comunidades vegetales acuáticas del Perú. Arnaldoa 3: 51-58.

GALÁN DE MERA, A. -1996- Relación entre los suelos y la vegetación del Perú. Arnaldoa 4: 87-94.

GALÁN DE MERA, A. -2007- Flora y vegetación de la Estación Biológica El Frío (Llanos Occidentales del Orinoco, Apure, Venezuela). Publicaciones de la Asociación Amigos del Coto de Doñana, Sevilla.

GALÁN DE MERA, A., S. BALDEÓN, H. BELTRÁN, M. BENAVENTE y J. GÓMEZ -2004- Datos sobre la vegetación del centro del Perú. Acta Bot. Malacitana 29: 89-115.

GALÁN DE MERA, A., C. CÁCERES y A. GONZÁLEZ -2002a- Las comunidades con Cactáceas del Sur del Perú, II. Nueva asociación y alianza del Desierto Pacífico. Acta Bot. Malacitana 27: 270-272.

GALÁN DE MERA, A., C. CÁCERES y A. GONZÁLEZ -2003a- La vegetación de la alta montaña andina del sur del Perú. Acta Bot. Malacitana 28: 121-147.

GALÁN DE MERA, A., C. CÁCERES y A.
GONZÁLEZ -2003b- Nuevas adiciones a la flora del Perú, III. Candollea 58: 325-337.

GALÁN DE MERA, A. y J. GÓMEZ CARRIÓN -2001- Las comunidades con Cactáceas del sur del Perú. Nuevos datos sobre la alianza Corryocaction brevistyli. Acta Bot. Malacitana 26: 240-246.

GALÁN DE MERA, A. y J. GÓMEZ CARRIÓN -2003-Comunidades de aerófitos: una aproximación fitosociológica sobre el desierto pacífico peruano. Doc. Phytosoc. 20: 127-133.

GALÁN DE MERA, A. y E. LINARES PEREA -2008- Datos sobre la vegetación de los humedales de América del Sur. De las sabanas bolivianas a los Llanos del Orinoco (Venezuela). Acta Bot. Malacitana 33: 1-18.

GALÁN DE MERA, A., M.V. ROSA y C. CÁCERES -2002b- Una aproximación sintaxonómica sobre la vegetación del Perú. Clases, órdenes y alianzas. Acta Bot. Malacitana 27: 75-103.

GALÁN DE MERA, A. y J.A. VICENTE ORELLANA -1996- Las comunidades con Corryocactus brevistylus del sur del Perú. Phytologia 80(1): 40-47.

GALÁNDEMERA,A.y J.A. VICENTEORELLANA -2006-Aproximación al esquema sintaxonómico de la vegetación de la región del Caribe y América del Sur. Anales Biol. 28: 3-27.

GALÁN DE MERA, A. \& J.A. VICENTE ORELLANA -2007-Cronosequences of vegetation- a bioclimatic theory for interpreting the patterns of relic vegetation types. Phytocoenologia 37: 471-494.

GALÁN DE MERA, A., J.A. VICENTE ORELLANA, J.A. LUCAS GARCÍA \& A. PROBANZA LOBO -1997- Phytogeographical sectoring of the Peruvian coast. Global Ecol. Biogeogr. Lett. 6: 349-367.

GUTTE, P. -1985- Beitrag zur Kenntnis zentralperuanischer Pflanzengesellschaften IV. Die grasreiche Vegetation der alpinen Stufe. Wiss. Z. Karl-Marx-Univ. Leipzig, Math.Naturwiss. R. 34(4): 357-401.

GUTTE, P. -1986- Beitrag zur Kenntnis zentralperuanischer Pflanzengesellschaften III. Pflanzengesellschaften der subalpinen Stufe. Feddes Repert. 97 (5-6): 319-371.

GUTTE, P. \& G.K. MÜLLER -1985- Salzpflanze ngesellschaften bei Cusco/Peru. Wiss. Z. Karl- 
Marx-Univ. Leipzig, Math.-Naturwiss. R. 34(4): 402-409.

HOLDRIDGE, L.R. -1960- Sistema para clasificar las formaciones del Mundo. Lima.

HORNUNG-LEONI, C.T. \& V. SOSA -2008Morphological phylogenetics of Puya subgenus Puya (Bromeliaceae). Bot. J. Linn. Soc. 156: 93-110.

HUBER, O. y R. RIINA -1997- Glosario Fitoecológico de las Américas. Vol. I. América del Sur: Paises hispanoparlantes. UNESCOFundación Instituto Botánico de Venezuela, Caracas.

HUECK, K. -1966- Die Wälder Südamerikas. Gustav Fischer, Stuttgart.

HUGUET DEL VILLAR, E. -1929- Geobotánica. Lábor, Barcelona.

IGM (INSTITUTO DE GEOLOGÍA Y MINERÍA) -1975- Mapa geológico del Perú. Lima.

IZCO, J. y M. DEL ARCO -2003-Código internacional de nomenclatura fitosociológica. Universidad de La Laguna.

JOHNSTON, I.M. -1929- Papers on the flora of northern Chile. Contrib. Gray Herb. 4: 1-172.

KOEPCKE, H-W. -1961- Synökologische Studien an der Westseite der peruanischen Anden. Ferd. Dümmlers, Bonn.

KOPECKÝ, K., J. DOSTALEK \& T. FRANTIK -1995- The use of the deductive method of syntaxonomic classification in the system of the vegetational units of the Braun-Blanquet approach. Vegetatio 117: 95-112.

KUENTZ, A., A. GALÁN DE MERA, M-P. LEDRU \& J-C. THOURET -2007- Phytogeographical data and modern pollen rain of the puna belt in southern Peru (Nevado Coropuna, Western Cordillera). J. Biogeogr. 34: 1762-1776.

LINARES-PALOMINO，R. -2003- The phytogeography of the seasonally dry tropical forests in Equatorial Pacific South America. Candollea 58: 473-499.

LINARES PEREA, E. -1991- Flora de la zona comprendida entre Yura y Chivay (2600 a 4800 msnm) Arequipa, 1987-1990. Universidad Nacional de San Agustín, Arequipa.

LINARES PEREA, E. -1997-Vegetación del Santuario Nacional Lagunas de Mejía. PRODENA, Arequipa.

LINARES PEREA, E. -2005- Flora Andina: Estudio
Botánico de Quebradas y Puna entre Arequipa y el Valle del Colca. Bol. Soc. Geogr. Lima 118: 91-144.

LINARES PEREA, E. y M.B. BENAVIDES 1995- Flora silvestre del transecto Yura-Chivay, Departamento de Arequipa. Bol. Lima 100: 211-254.

LÓPEZ GUILLÉN, J. y S. RIVAS GODAY -1952Preferencias edáficas de la Distichlis spicata (L.) Greene, en los "gramadales" de Conchán (Lima, Perú). Anales Jard. Bot. Madrid 10: 605-618.

LUEBERT, F. -2006- Apuntes sobre la vegetación de bosque y matorral del desierto precordillerano de Tarapacá (Chile). Chloris Chilensis 7 [www. chlorischile.cl]

LUEBERT, F. y R. GAJARDO -2000- Vegetación de los Andes áridos del norte de Chile. Lazaroa 21: 111-130.

LUEBERT, F. y R. GAJARDO -2005- Vegetación alto andina de Parinacota (norte de Chile) y una sinopsis de la vegetación de la Puna meridional. Phytocoenologia 35: 79-128.

MCVAUGH, R. -1963- Tropical American Myrtaceae, II. Notes on generic concepts and description of previously unrecognized species. Fieldiana, Bot. 29: 393-532.

MARCELO PEÑA, J.L., I. SÁNCHEZ VEGA y J.F. MILLÁN TAPIA -2006- Estado actual de la diversidad florística del Páramo, sectores: El Espino y Palambe, Sallique, Jaén, Cajamarca, Perú. Ecol. Apl. 5: 1-8.

MÜLLER, G.K. -1985a- Die Pflanzengesellschaften der Loma-Gebiete Zentralperus. Wiss. Z. KarlMarx-Univ. Leipzig, Math.-Naturwiss. R. 34: 317-356.

MÜLLER, G.K. -1985b- Zur floristichen Analyse der peruanischen Loma-Vegetation. Flora 176 : 153-165.

MÜLLER, G.K. -1988-Anthropogene Veränderungen der Loma-Vegetation Perus. Flora 180: 37-40.

MÜLLER, G.K. \& P. GUTTE -1983- Beiträge zur Kenntnis der Halophytengesellschaften der peruanischen Küstenregion. Wiss. Z. KarlMarx-Univ. Leipzig, Math.-Naturwiss. R. 32: 502-514.

MÜLLER, G.K. \& P. GUTTE -1985- Beiträge zur Kenntnis der Vegetation der Flußauen, Sümpfe und Gewässer der zentralperuanischen Küstenregion. Wiss. Z. Karl-Marx-Univ. Leipzig, 
Math.-Naturwiss. R. 34(4): 410-429.

NAVARRO, G. -1993- Vegetación de Bolivia: el Altiplano meridional. Rivasgodaya 7: 69-98.

NAVARRO, G. y M. MALDONADO -2005Geografía ecológica de Bolivia. Vegetación y Ambientes Acuáticos. Fundación Simón I. Patiño, Santa Cruz.

NICHOLSON, C. -1939- Fitogeografía general. Arequipa.

PHILLIPS, O. \& J.S. MILLER -2002- Global Patterns of Plant Diversity : Alwyn H. Gentry's Forest Transect Data Set. Missouri Botanical Garden Press, St. Louis.

POPENOE, H., S.R. KING, J. LEÓN \& L.S. KALINOWSKI -1989- Lost Crops of the Incas. National Academy Press, Washington.

PUIG, H., A. FABRE, M-F. BELLAN, D. LACAZE, F. VILLASANTE \& A. ORTEGA -2002Déserts et richesse floristique: les lomas du sud péruvien, un potentiel à conserver. Sécheresse $13: 215-225$.

PULGAR VIDAL, J. -1996- Geografía del Perú. Peisa, Lima.

RANGEL, O. y J. AGUIRRE -1983- Comunidades acuáticas altoandinas- I. Vegetación sumergida y de ribera en el lago de Tota, Boyacá, Colombia. Caldasia 13: 719-742.

RAUH, W. -1979- Perú. País de contrastes. Bol. Lima 1-2: 1-24.

RITTER, F. -1981- Kakteen in Südamerika. Band. 4. Fiedrich Ritter Selbstverlag, Spangenberg.

RIVAS-MARTÍNEZ, S. -2007- Mapa de series, geoseries y geopermaseries de vegetación de España [Memoria del mapa de vegetación potencial de España]. Parte I. Itinera Geobot. 17: 5-435.

RIVAS-MARTÍNEZ, S. -2009- Global Bioclimatics (www.globalbioclimatics.org).

RIVAS-MARTÍNEZ, S., D. SÁNCHEZ-MATA \& M. COSTA -1999- North American Boreal and Western temperate Forest Vegetation (Syntaxonomical sinopsis of the potential natural plant communities of North America, II). Itinera Geobot. 12: 5-316.

RIVAS-MARTÍNEZ, S. y O. TOVAR -1982Vegetatio Andinae, I. Datos sobre las comunidades vegetales altoandinas de los Andes Centrales del Perú. Lazaroa 4: 167-187. RIVAS-MARTÍNEZ, S., O. TOVAR y A. GALÁN
DE MERA-1988-Pisos bioclimáticos y cultivos del Perú. ICI-INP, Madrid.

RUNDEL, P.W., M.O. DILLON, B. PALMA, H.A. MOONEY, S.L. GULMON \& J.R. EHLERINGER -1991- The phytogeography and ecology of the coastal Atacama and Peruvian deserts. Aliso 13: 1-49.

SAGÁSTEGUI ALVA, A. y S. LEIVA GONZÁLEZ -1993- Flora invasora de los cultivos del Perú. Edición de A. Sagástegui, Trujillo.

SÁNCHEZ VEGA, I., M. CABANILLAS SORIANO, A. MIRANDA LEIVA, W. POMA ROJAS, J. DÍAZ NAVARRO, F. TERRONES HERNÁNDEZ y H. BAZÁN ZURITA -2005La Jalca, el ecosistema frío del noroeste peruano. Fundamentos biológicos y ecológicos. Minera Janacocha-Geográfica EIRL, Lima. SAN MARTÍN PADOVANI, C., R. MEDINA JARAMILLO, P. OJEDANEMPUy C. RAMÍREZ GARCÍA-1993-La biodiversidad vegetacional del santuario de la naturaleza "Río Cruces" (Valdivia, Chile). Acta Bot. Malacitana 18: 259-279.

SCHUYLER, A.E. -1974- Typification and application of the names Scirpus americanus Pers., S. olneyi Gray, and S. pungens Vahl. Rhodora 76: 51-52.

SEIBERT, P. \& X. MENHOFER -1991- Die Vegetation des Wohngebietes der Kallawaya und des Hochlandes von Ulla-Ulla in den bolivianischen Anden. I. Phytocoenologia 20: 145-276.

SEIBERT, P. \& X. MENHOFER -1992- Die Vegetation des Wohngebietes der Kallawaya und des Hochlandes von Ulla-Ulla in den bolivianischen Anden. II. Phytocoenologia 20: 289-438.

SOLOMON, J. -2009-W3 TROPICOS. Nomenclatural Data Base. Missouri Botanical Garden, St. Louis (http://www.tropicos.org/).

SOUKUP, J. -1987-Vocabulario de los nombres vulgares de la flora peruana y catálogo de los géneros. Editorial Salesiana, Lima.

TOVAR, O. -1993- Las Gramíneas (Poaceae) del Perú. Ruizia 13: 9-480.

TOVAR, O. -2002-Enciclopedia temática del Perú. La flora peruana. Milla Batres, Lima.

TREACY, J.M. -1994- Las chacras de Coporaque. Andenería y riego en el valle del Colca. Instituto de Estudios Peruanos, Lima.

WEBERBAUER, A. -1936- Phytogeography of 
the Peruvian Andes. In: J.F. MACBRIDE -ed.Flora of Peru 13(1): 13-81. Field Museum of Natural History, Chicago.

WEBERBAUER, A. -1945- El mundo vegetal de los Andes Peruanos (Estudio fitogeográfico). Ministerio de Agricultura, Lima.
WEIGEND, M., E.F. RODRÍGUEZ y C. ARANA -2005- Los bosques relictos del noroeste del Perú y suroeste de Ecuador. Rev. Peru. Biol. 12(2): 185-194.

WOOD, J.R.I. -2008- A revision of Tecoma Juss. (Bignoniaceae) in Bolivia. Bot. J. Linn. Soc. 156: 143-172. 